\title{
Maximum fluorescence and electron transport kinetics determined by light-induced fluorescence transients (LIFT) for photosynthesis phenotyping
}

\author{
Beat Keller ${ }^{1,3}$ (1) $\cdot$ Imre Vass $^{2} \cdot$ Shizue Matsubara ${ }^{1} \cdot$ Kenny Paul $^{2} \cdot$ Christoph Jedmowski $^{1} \cdot$ Roland Pieruschka $^{1}$. \\ Ladislav Nedbal $^{1}$. Uwe Rascher ${ }^{1}$. Onno Muller ${ }^{1}$
}

Received: 10 November 2017 / Accepted: 9 October 2018 / Published online: 24 October 2018

(c) The Author(s) 2018

\begin{abstract}
Photosynthetic phenotyping requires quick characterization of dynamic traits when measuring large plant numbers in a fluctuating environment. Here, we evaluated the light-induced fluorescence transient (LIFT) method for its capacity to yield rapidly fluorometric parameters from $0.6 \mathrm{~m}$ distance. The close approximation of LIFT to conventional chlorophyll fluorescence $(\mathrm{ChlF})$ parameters is shown under controlled conditions in spinach leaves and isolated thylakoids when electron transport was impaired by anoxic conditions or chemical inhibitors. The ChlF rise from minimum fluorescence $\left(F_{\mathrm{o}}\right)$ to maximum fluorescence induced by fast repetition rate $\left(F_{\mathrm{m}-\mathrm{FRR}}\right)$ flashes was dominated by reduction of the primary electron acceptor in photosystem II $\left(\mathrm{Q}_{\mathrm{A}}\right)$. The subsequent reoxidation of $\mathrm{Q}_{\mathrm{A}}{ }^{-}$was quantified using the relaxation of ChlF in $0.65 \mathrm{~ms}\left(F_{\mathrm{r} 1}\right)$ and $120 \mathrm{~ms}\left(F_{\mathrm{r} 2}\right)$ phases. Reoxidation efficiency of $\mathrm{Q}_{\mathrm{A}}{ }^{-}\left(F_{\mathrm{r} 1} / F_{\mathrm{v}}\right.$, where $\left.F_{\mathrm{v}}=F_{\mathrm{m}-\mathrm{FRR}}-F_{\mathrm{o}}\right)$ decreased when electron transport was impaired, while quantum efficiency of photosystem II $\left(F_{\mathrm{v}} / F_{\mathrm{m}}\right)$ showed often no significant effect. ChlF relaxations of the LIFT were similar to an independent other method. Under increasing light intensities, $F_{\mathrm{r} 2}{ }^{\prime} / F_{\mathrm{q}}{ }^{\prime}$ (where $F_{\mathrm{r} 2}{ }^{\prime}$ and $F_{\mathrm{q}}{ }^{\prime}$ represent $F_{\mathrm{r} 2}$ and $F_{\mathrm{v}}$ in the light-adapted state, respectively) was hardly affected, whereas the operating efficiency of photosystem II $\left(F_{\mathrm{q}}{ }^{\prime} / F_{\mathrm{m}}{ }^{\prime}\right)$ decreased due to non-photochemical quenching. $F_{\mathrm{m}-\mathrm{FRR}}$ was significantly lower than the ChlF maximum induced by multiple turnover $\left(F_{\mathrm{m}-\mathrm{MT}}\right)$ flashes. However, the resulting $F_{\mathrm{v}} / F_{\mathrm{m}}$ and $F_{\mathrm{q}}{ }^{\prime} / F_{\mathrm{m}}{ }^{\prime}$ from both flashes were highly correlated. The LIFT method complements $F_{\mathrm{v}} / F_{\mathrm{m}}$ with information about efficiency of electron transport. Measurements in situ and from a distance facilitate application in high-throughput and automated phenotyping.
\end{abstract}

Keywords Fluorescence transient $\cdot$ Photosynthesis $\cdot$ Fast repetition rate $\cdot$ Electron transport kinetics

Electronic supplementary material The online version of this article (https://doi.org/10.1007/s11120-018-0594-9) contains supplementary material, which is available to authorized users.

Beat Keller

beat.keller@usys.ethz.ch

1 Institute of Bio- and Geosciences, IBG-2: Plant Sciences, Forschungszentrum Jülich GmbH, 52425 Jülich, Germany

2 Institute of Plant Biology, Biological Research Center, 6726 Szeged, Hungary

3 Present Address: Molecular Plant Breeding, ETH Zürich, 8092 Zurich, Switzerland

\section{Introduction}

Photosynthetic processes, from light absorption by the chlorophyll-based pigments through charge separation in the photosystem II (PSII) reaction centers and sequential electron transport, are related to the redox state of the primary quinone electron acceptor $\left(\mathrm{Q}_{\mathrm{A}}\right)$ and coupled to the signature of chlorophyll fluorescence (ChlF) (Kautsky and Hirsch 1931; Baker 2008; Müh et al. 2012). Based on ChlF, parameters such as the maximum quantum efficiency of PSII $\left(F_{\mathrm{v}} / F_{\mathrm{m}}\right)$ and non-photochemical quenching (NPQ) estimating the proportion of absorbed light energy utilized for PSII photochemistry and non-photochemical energy dissipation, respectively, were established (Butler 1978; Baker 2008; Lazár 2013). The quick assessment of ChlF makes this signal a powerful tool for plant phenotyping (Furbank and Tester 2011; Fiorani and Schurr 2013). Phenotyping 
requires characterization of a large plant set which needs to be completed before significant changes in the measured traits occur. This is particularly difficult when phenotyping photosynthesis because this process is highly dynamic and sensitive to environmental conditions (Ananyev et al. 2005a; Kono and Terashima 2014).

In order to determine $F_{\mathrm{v}} / F_{\mathrm{m}}$, the ChlF signal is compared under conditions when $\mathrm{Q}_{\mathrm{A}}$ is in a fully oxidized state resulting in minimal ChlF $\left(F_{\mathrm{o}}\right)$ respective to the fully reduced state resulting in maximal $\mathrm{ChlF}\left(F_{\mathrm{m}}\right)$. Two approaches using strong light pulses are widely accepted to reduce $\mathrm{Q}_{\mathrm{A}}$ fully: the single turnover flash (STF) and the multiple turnover flash (MTF) (Kalaji et al. 2017). A saturating STF has to provide high enough excitation power to induce one single charge separation in all PSII reaction centers and fully reduce $\mathrm{Q}_{\mathrm{A}}$ in order to yield maximum ChlF level $\left(F_{\mathrm{m}-\mathrm{ST}}\right)$ (Malkin and Kok 1966; Schreiber 1986a; Samson and Bruce 1996; Kolber et al. 1998; Steffen et al. 2001). The excitation flash needs to be short enough (from fs to few $\mu \mathrm{s}$ ) to prevent reoxidation of $\mathrm{Q}_{\mathrm{A}}{ }^{-}$and reexcitation of PSII reaction centers (Malkin and Kok 1966; Belyaeva et al. 2014). In contrast, a saturating MTF requires at least 0.2-s duration of excitation at a few $1000 \mu \mathrm{mol}$ photons $\mathrm{m}^{-2} \mathrm{~s}^{-1}$ (Ögren and Baker 1985; Schreiber et al. 1986b; Schreiber 2004). Within this time range, $Q_{A}$ is reduced and reoxidized several times followed by reduction of the plastoquinone (PQ) pool and electron transfer to Photosystem I (PSI) (Vernotte et al. 1979; Schansker et al. 2005). MTFs ultimately result in an about 50\% higher maximum ChlF level $\left(F_{\mathrm{m}-\mathrm{MT}}\right)$ compared to $F_{\mathrm{m}-\mathrm{ST}}$ (Schreiber 1986a; Schreiber et al. 1986b; Schansker et al. 2011). The difference between $F_{\mathrm{m}-\mathrm{ST}}$ and $F_{\mathrm{m}-\mathrm{MT}}$ was named the thermal phase because it is dependent on temperature, i.e., it is rate-limited (Delosme 1967). Later, the ChlF rise of the thermal phase was related to electron transport kinetics, particularly the accumulation of secondary quinone acceptors $\left(\mathrm{Q}_{\mathrm{B}}\right)$ in a reduced state (Strasser et al. 1995; Lazár 2006). However, the origin of the thermal phase is not yet localized due to the complex and overlying kinetics of different electron transport processes (Rascher and Nedbal 2006; Müh et al. 2012) and the probable involvement of additional ChlF quenchers (Schansker et al. 2011, 2014; Prášil et al. 2018; Magyar et al. 2018).

Alternatively, electron transport kinetics in the darkadapted state were studied by following reoxidation of $\mathrm{Q}_{\mathrm{A}}{ }^{-}$coupled to ChlF relaxation after a STF (Vass et al. 1999; Petrouleas and Crofts 2005). According to an exponential decay model with three time constants, ChlF relaxes due to electron transport from $\mathrm{Q}_{\mathrm{A}}{ }^{-}$to $\mathrm{Q}_{\mathrm{B}}$ with a time constant $\left(\tau_{1}\right)$ of $0.1-0.2 \mathrm{~ms}$ when the $\mathrm{Q}_{\mathrm{B}}$ site is occupied by a PQ (Bowes and Crofts 1980; Vass et al. 1999; Shinkarev 2004; Petrouleas and Crofts 2005). The second exponential component represents the reoxidation of $\mathrm{Q}_{\mathrm{A}}{ }^{-}$which had initially no PQ molecule bound (Taoka and Crofts 1990; Petrouleas and Crofts 2005). Therefore, this time constant $\left(\tau_{2}\right)$ represents the binding of PQ molecule to the $\mathrm{Q}_{\mathrm{B}}$ site of PSII and is estimated to be between 2.2 and $10 \mathrm{~ms}$ (Vass et al. 1999; Eshaghi et al. 2000). The third component $\left(\tau_{3}\right)$ is slow (500 ms to seconds) and interpreted as a back reaction from $\mathrm{Q}_{\mathrm{A}}{ }^{-}$to the donor side components of PSII, specifically the $\mathrm{S}_{2}$ state of the oxygen evolving complex (OEC) (Robinson and Crofts 1983; Vass et al. 1999). Most of the existing ChlF-based techniques apply STFs either from a measuring head in direct contact with the leaf surface, or from a few cm distance. $F_{\mathrm{m}-\mathrm{ST}}$ is then recorded from a dark-adapted sample with an oxidized electron transport chain (Vernotte et al. 1979; Schansker et al. 2014). This allows standardized examination and modeling of ChlF relaxation kinetics in the dark (Vass et al. 1999). However, these requirements are impractical under conditions of ambient illumination, specifically when the presence of light is required for manifestation of stress conditions in the targeted plants. One such example is temperature stress, where low temperature enhances the photodamage effects of excess light (Pieruschka et al. 2010). In addition, the conventional fluorometric techniques may not provide sufficient resolution and throughput to capture highly dynamic regulation of photosynthesis.

The light-induced fluorescence transient (LIFT) method probes PSII from a distance using subsaturating (actinic) measuring flashlets in fast repetition rate (FRR) (Kolber et al. 1998; Osmond et al. 2017). In contrast to other techniques, no separate saturating flash is required in the LIFT method because the FRR probe flashlets are used directly for that purpose. The short measuring time of $0.2 \mathrm{~s}$ allows integration into automated systems for phenotyping in high spatio-temporal resolution. Following application in marine research (Kolber et al. 1998; Suggett et al. 2001; Oxborough et al. 2012; Robinson et al. 2014), a stationary LIFT system was installed for monitoring plant canopy from a distance of $50 \mathrm{~m}$ using laser excitation (Pieruschka et al. 2010, 2014; Raesch et al. 2014). Operating efficiency of PSII $\left(F_{\mathrm{q}}{ }^{\prime} / F_{\mathrm{m}}{ }^{\prime}\right)$ measured with this previous LIFT system correlated well with pulse amplitude modulation (PAM) measurements $\left(R^{2}=0.89\right)$ and $\mathrm{CO}_{2}$ assimilation rates $\left(R^{2}=0.94\right)$ (Ananyev et al. 2005a; Pieruschka et al. 2010, 2014).

Here, we evaluated a newly developed LIFT device for its capacity to yield robust fluorometric parameters useful in plant phenotyping. Parameters as maximum $\mathrm{ChlF}$ induced by FRR flash $\left(F_{\mathrm{m}-\mathrm{FRR}}\right)$ and $\mathrm{Q}_{\mathrm{A}}{ }^{-}$reoxidation efficiency in $0.65 \mathrm{~ms}\left(F_{\mathrm{rl}} / F_{\mathrm{v}}\right)$ and $120 \mathrm{~ms}\left(F_{\mathrm{r} 2} / F_{\mathrm{v}}\right)$ relaxation phases were introduced. The parameters were determined in isolated thylakoids and intact plants subjected to different treatments (electron transport inhibitors, anaerobiosis, or light) and approximated well-established ChlF parameters. 


\section{Materials and methods}

\section{Plant cultivation}

In total, 36 spinach (Spinacia oleracea) plants of genotype Matador were grown in the greenhouse in Jülich, Germany, under $16-\mathrm{h} / 8$-h day/night cycle at $20^{\circ} \mathrm{C} / 18{ }^{\circ} \mathrm{C}$. Light intensity was kept automatically between 60 and $300 \mu \mathrm{mol}$ photons $\mathrm{m}^{-2} \mathrm{~s}^{-1}$ using additional lamps or shading nets. 400-mL pots were filled with a turf-clay substrate (ED73, Einheitserdewerke, Sinntal-Altengronau, Germany). Plants were watered automatically twice a day during cultivation. Measurements were performed using plants 28 or 32 days after sowing.

\section{Isolation of thylakoids and PSII enriched membrane particles}

For isolation of spinach thylakoids and PSII-enriched thylakoid membrane particles (BBY particles), fresh spinach leaves were bought from a local supermarket in Szeged, Hungary, and prepared as described in Berthold et al. (1981). For measurements with LIFT and FL3000, the final concentration of thylakoids was adjusted to equivalent chlorophyll $a$ concentration of $10 \mu \mathrm{M}\left(\sim 10 \mu \mathrm{g} \mathrm{mL}^{-1}\right)$.

\section{DCMU and DBMIB treatment}

To manipulate the ChlF relaxation kinetics in thylakoid samples, we used 3-(3,4-dichlorophenyl)-1,1-dimethylurea (DCMU) and 2,5-dibromo-5-methyl-6-isopropyl-benzoquinone (DBMIB), which inhibit selectively the reoxidation of $\mathrm{Q}_{\mathrm{A}}{ }^{-}$in PSII and of $\mathrm{PQH}_{2}$ at the cytb $\mathrm{f}_{6}$ complex, respectively (Lazár et al. 2001; Kurisu et al. 2003). A thylakoid suspension of $3 \mathrm{~mL}$ was transferred to transparent plastic cuvettes. After 5-min dark-adaption, DCMU and DBMIB were added to final concentration of $5 \mu \mathrm{M}\left(1.17 \mu \mathrm{g} \mathrm{mL}^{-1}\right)$ and $0.66 \mu \mathrm{M}$ $\left(0.213 \mu \mathrm{g} \mathrm{mL}^{-1}\right)$, respectively. Samples were stirred manually and followed by either LIFT or FL3000 measurements using FRR flash for $0.75 \mathrm{~ms}\left(\mathrm{FRRF}_{0.75 \mathrm{~ms}}\right)$ or STF, respectively. The number of technical replicates was 3-5. In addition, intact leaves were treated with DCMU to observe ChlF induction curves under conditions of blocked electron transport between $\mathrm{Q}_{\mathrm{A}}$ and $\mathrm{Q}_{\mathrm{B}}$. Plants were dark-adapted overnight, then fully expanded leaves were left untreated or were subjected to $200 \mu \mathrm{M}$ DCMU in $50 \mathrm{~mL}$ Milli-Q water (Tóth et al. 2005). The control was left untreated because a control with $1 \%$ ethanol in distilled water showed no effect on $F_{\mathrm{m}}$ and little effect on the ChlF rise compared to untreated leaves (Tóth et al. 2005). However, no ethanol was used in the DCMU solution to avoid possible side effects (Haldimann and Tsimilli-Michael 2005). DCMU was grinded to powder in order to dissolve it better in water. In the dark, one leaf per plant was left for $6 \mathrm{~h}$ in DCMU solution, then wiped and left for $30 \mathrm{~min}$ in the air. Measurements on attached leaves were done using $5 \mathrm{FRRFs}_{0.75 \mathrm{~ms}}$ followed by one MTF for $750 \mathrm{~ms}\left(\mathrm{MTF}_{750 \mathrm{~ms}}\right)$. Only the first of the 5 FRRFs $_{0.75 \mathrm{~ms}}$ is shown in the result section. Measurements were replicated with six different plants.

\section{Anaerobic treatment under nitrogen atmosphere}

Oxygen depletion inhibits the plastid terminal oxidase (PTOX), which normally keeps PQ in an oxidized state in the dark (Bohme et al. 1971; Cournac et al. 2000; Feilke et al. 2014). Anoxic treatment was used to manipulate the level of PQ reduction non-invasively in living plants (Tóth et al. 2007b). The anoxic atmosphere was maintained in the LI-COR 6400 transparent $2 \times 3 \mathrm{~cm}$ chamber head (LI-COR, Inc., Nebraska USA) using nitrogen gas $\left(\mathrm{N}_{2}\right)$. Air inflow into the chamber came either from the ambient air (as control, with 400 ppm $\mathrm{CO}_{2}$ ) or from $\mathrm{N}_{2}$ gas supply without oxygen (containing $<1.5 \mathrm{ppm} \mathrm{CO}_{2}$ ). The air flow rate during the measurements was $300 \mu \mathrm{mol}$ air s ${ }^{-1}$, and the block temperature of the LI-COR was kept at $20{ }^{\circ} \mathrm{C}$. Prior to measurements, plants were dark-adapted overnight. A fully expanded leaf was inserted into the chamber and measured with the LIFT instrument through the transparent front window. Measurements were started after 5-min exposure to control or $\mathrm{N}_{2}$ atmosphere using $5 \mathrm{FRRFs}_{0.75 \mathrm{~ms}}$ followed by one $\mathrm{MTF}_{750 \mathrm{~ms}}$. After another $5 \mathrm{~min}$, measurements were repeated using 5 FRR flashes for $2.5 \mathrm{~ms}\left(\mathrm{FRRFs}_{2.5 \mathrm{~ms}}\right)$. Each first flash of the $5 \mathrm{FRRFs}_{0.75 \mathrm{~ms}}$ and $5 \mathrm{FRRFs}_{2.5 \mathrm{~ms}}$ is shown the result section. Measurements were replicated with six different plants.

\section{Light response curves}

To study electron transport kinetics of light-adapted plants, control plants of the $\mathrm{N}_{2}$ atmosphere experiment were subjected to increasing levels of blue light provided by the LED (445 nm) light source of the LIFT instrument. The size of the illumination spot was around $3 \mathrm{~cm}^{2}$. A light response measurement consisted of a total of $160 \mathrm{FRRF}_{0.75 \mathrm{~ms}}$ triggered at a 5-s interval. At every light intensity (30, 100, 300, $700 \mu \mathrm{mol}$ photons $\mathrm{m}^{-2} \mathrm{~s}^{-1}$ ), ChlF was monitored over a period of $200 \mathrm{~s}$ by applying 40 consecutive FRRF $_{0.75 \mathrm{~ms}}$. Light response curves were replicated with six different plants.

\section{Fluorescence measurements}

Different methods have been developed to separate absolute ChlF intensity and background radiation from relative 
changes of ChlF yield due to $\mathrm{Q}_{\mathrm{A}}$ reduction. This allows comparison of minimal ChlF ( $F_{\mathrm{o}}$ in dark-adapted state, and $F^{\prime}$ in background light) and maximal $\mathrm{ChlF}\left(F_{\mathrm{m}}\right.$ in dark-adapted state, and $F_{\mathrm{m}}{ }^{\prime}$ in background light) at initial redox state of $\mathrm{Q}_{\mathrm{A}}$ and when $\mathrm{Q}_{\mathrm{A}}$ is fully reduced at the end of a saturating flash, respectively (Schreiber et al. 1986a; Strasser et al. 1995; Kolber et al. 1998). Two different fluorometers as described below were used in this study. The LIFT method requires no additional saturating light pulse besides the measuring flashlets. Therefore, it is referred to as a modulated method. In contrast, the FL3000 fluorometer uses weak measuring pulses and a strong excitation flash. Therefore, it is referred to as a double-modulated method.

\section{FL3000 measurements}

ChlF relaxation after a STF was monitored by weak, nonactinic measuring flashes in increasing time intervals (Trtilek et al. 1997; Vass et al. 1999). These double-modulated ChlF measurements were performed with a FL3000 fluorometer (Photon Systems Instruments Ltd., Brno, Czech Republic) (Trtilek et al. 1997). The instrument is equipped with red LEDs $(639 \mathrm{~nm})$ for both actinic $(20 \mu$ s with an excitation power of $1020 \mu \mathrm{mol}$ photons $\mathrm{m}^{-2} \mathrm{~s}^{-1}$ ) and weak, non-actinic measuring flashes of $8 \mu \mathrm{s}$, with a measuring delay of $7 \mu \mathrm{s}$. Changes in ChlF yield can be measured in a very broad time range, from $100 \mu$ s to $100 \mathrm{~s}$. Within this time range, reoxidation of $\mathrm{Q}_{\mathrm{A}}{ }^{-}$by both forward and backward reactions can be studied (Vass et al. 1999). The reoxidation phase after the STF usually shows three relaxation phases with corresponding $\tau_{1}, \tau_{2}$, and $\tau_{3}$ time constants.

\section{LIFT measurements}

The newly developed compact LIFT instrument (Version LIFT-REM, Soliense Inc., New York, USA) is equipped with a blue LED (445 nm) excitation source. Excitation protocols composed of up to 7500 flashlets are used to manipulate the level of photosynthetic activity and ChlF (Fig. 1). ChlF emission is detected at $685( \pm 10) \mathrm{nm}$. The LIFT device monitors any background signal in the detector range during inter-flashlet periods and subtracts this signal from the in-flashlet ChlF signal. The ChlF yield is internally normalized against excitation power of each flashlet to correct for smaller fluctuations. Flashlet excitation power along the entire FRR excitation phase is kept at a constant level. This was verified by observing a flat fluorescence transient using a fluorescence standard with constant quantum yield of fluorescence.

All measurements were done from a $0.6 \mathrm{~m}$ distance with flashlet length of $1.6 \mu$ s. The three used FRR flashes differ in the length of flashlet interval and ChlF induction phase (Table 1). FRRF $_{0.75 \mathrm{~ms}}$ consists of 300 flashlets with a $2.5-\mu \mathrm{s}$

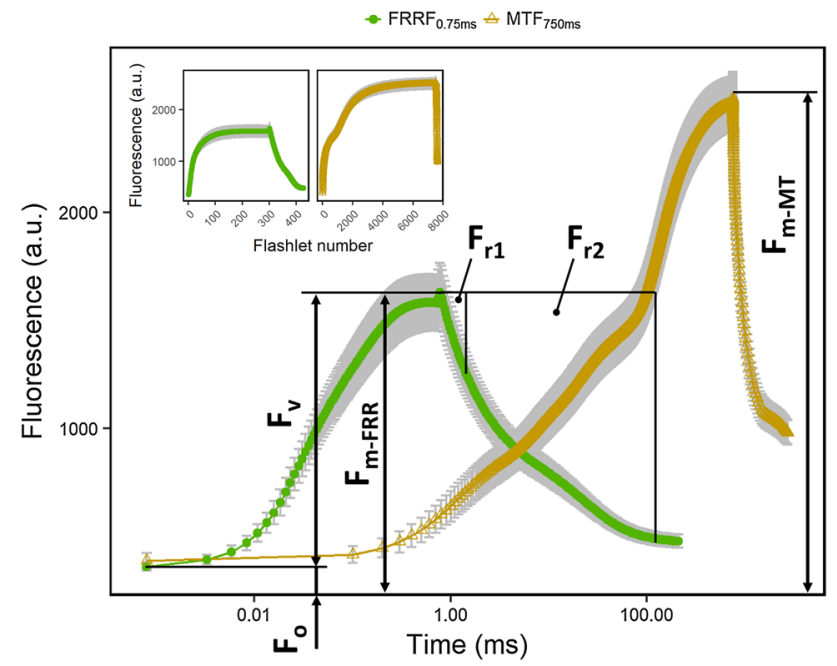

Fig. 1 Chlorophyll fluorescence transients of spinach leaves induced by fast repetition rate flash $\left(\mathrm{FRRF}_{0.75 \mathrm{~ms}}\right)$ and multiple turnover flash $\left(\mathrm{MTF}_{750 \mathrm{~ms}}\right)$ are presented on a logarithmic time scale. The $\mathrm{FRRF}_{0.75 \mathrm{~ms}}$ protocol (green circles) consists of 300 subsaturating flashlets $\left(40,000 \mu \mathrm{mol}\right.$ photons $\left.\mathrm{m}^{-2} \mathrm{~s}^{-1}\right)$ in the first $0.75 \mathrm{~ms}$ to saturate maximum fluorescence $\left(F_{\mathrm{m}-\mathrm{FRR}}\right)$. Minimum fluorescence $\left(F_{\mathrm{o}}\right)$, $F_{\text {m-FRR }}$, and variable fluorescence $\left(F_{\mathrm{v}}\right)$ were used for calculation of the quantum efficiency of photosystem II $\left(F_{\mathrm{v}} / F_{\mathrm{m}}\right)$ in the dark-adapted state. The excitation flash is followed by 127 flashlets at exponential decreasing repetition rate resulting in chlorophyll fluorescence relaxation. The area above this relaxation curve was restricted by two time period $\left(r_{1}=0.65 \mathrm{~ms}\right.$ and $r_{2}=120 \mathrm{~ms}$ after $F_{\mathrm{m}-\mathrm{FRR}}$ was reached) resulting in two relaxation phases $\left(F_{\mathrm{r} 1}\right.$ and $\left.F_{\mathrm{r} 2}\right)$. The areas were normalized with the corresponding time period and with $F_{\mathrm{v}}$ in order to retrieve the reoxidation efficiency of the primary quinone acceptor $\left(\mathrm{Q}_{\mathrm{A}}\right)$ in the given relaxation phases $\left(F_{\mathrm{r} 1} / F_{\mathrm{v}}\right.$ and $\left.F_{\mathrm{r} 2} / F_{\mathrm{v}}\right)$. The $\mathrm{MTF}_{750 \mathrm{~ms}}$ (yellow triangles) protocol consists of 7500 subsaturating flashlets $\left(1000 \mu \mathrm{mol}\right.$ photons $\left.\mathrm{m}^{-2} \mathrm{~s}^{-1}\right)$ in the first $750 \mathrm{~ms}$ and induced the maximum fluorescence $\left(F_{\mathrm{m}-\mathrm{MT}}\right)$. Inset: Chlorophyll fluorescence transients against flashlet number of $\mathrm{FRRF}_{0.75 \mathrm{~ms}}$ and $\mathrm{MTF}_{750 \mathrm{~ms}}$ are shown. Error bars show standard deviation of the mean ( $n=6$ plants). (Color figure online)

interval summing up to the $0.75 \mathrm{~ms}$ induction phase. The ChlF relaxation phase after the $\mathrm{FRRF}_{0.75 \mathrm{~ms}}$ consists of 127 flashlets. The interval between those flashlets increases exponentially with

$j_{i}=10^{1.28+0.0215 \times i} \mu \mathrm{s}$,

where $j_{i}$ is the interval length of the $i$ th flashlet. For the DCMU and DBMIB experiments, the excitation power was approximately $20,000 \mu \mathrm{mol}$ photons $\mathrm{m}^{-2} \mathrm{~s}^{-1}$ for the ChlF induction phase using $\mathrm{FRRF}_{0.75 \mathrm{~ms}}$. Due to the restricted excitation power of the LEDs, the FRRF $\mathrm{F}_{0.75 \mathrm{~ms}}$ lasts longer than a proper STF in order to get $F_{\mathrm{m}-\mathrm{FRR}}$ saturated. For intact plants, the excitation power was $40,000,24,000$, and $1000 \mu \mathrm{mol}$ photons $\mathrm{m}^{-2} \mathrm{~s}^{-1}$ for the ChlF induction phase using $\mathrm{FRRF}_{0.75 \mathrm{~ms}}, \mathrm{FRRF}_{2.5 \mathrm{~ms}}$, and $\mathrm{MTF}_{750 \mathrm{~ms}}$, respectively. The interval between the flashlets for $\mathrm{MTF}_{750 \mathrm{~ms}}$ was extended from 2.5 to $100 \mu$ s due to exhausting of LED at 
Table 1 Different excitation protocols are shown: Fast repetition rate flash for $0.75 \mathrm{~ms}\left(\mathrm{FRRF}_{0.75 \mathrm{~ms}}\right)$ and for $2.5 \mathrm{~ms}\left(\mathrm{FRRF}_{2.5 \mathrm{~ms}}\right)$ as well as saturating multiple turnover flash for $750 \mathrm{~ms}\left(\mathrm{MTF}_{750 \mathrm{~ms}}\right)$. In the induction phase, flashlet interval is constant for given amount of flashlets and interval, while it increases exponentially in the relaxation phase to allow reoxidation of the primary quinone acceptor $\left(\mathrm{Q}_{\mathrm{A}}\right)$. Flashlet length is always $1.6 \mu$ s and has in all flashes the same specified excitation power

\begin{tabular}{|c|c|c|c|c|c|c|}
\hline Excitation protocol & $\begin{array}{l}\text { Induction } \\
\text { phase (ms) }\end{array}$ & $\begin{array}{l}\text { Number of flashlets in } \\
\text { induction phase }\end{array}$ & $\begin{array}{l}\text { Flashlet interval in } \\
\text { induction phase }(\mu \mathrm{s})\end{array}$ & $\begin{array}{l}\text { Relaxation } \\
\text { phase (ms) }\end{array}$ & $\begin{array}{l}\text { Number of flashlets in } \\
\text { relaxation phase }\end{array}$ & $\begin{array}{l}\text { Flashlet } \\
\text { length } \\
(\mu \mathrm{s})\end{array}$ \\
\hline $\mathrm{FRRF}_{0.75 \mathrm{~ms}}$ & 0.75 & 300 & 2.5 & 209 & 127 & 1.6 \\
\hline $\mathrm{FRRF}_{2.5 \mathrm{~ms}}$ & 2.5 & 1000 & 2.5 & 209 & 127 & 1.6 \\
\hline $\mathrm{MTF}_{750 \mathrm{~ms}}$ & 750 & 7500 & 100 & 1975 & 127 & 1.6 \\
\hline
\end{tabular}

longer flashes. This resulted in the lower excitation power. Excitation power was measured at $1 \%$ duty cycle using a 5-s calibration flash measured by a quantum sensor (LI-190R, LI-COR, Inc.) and then extrapolated to $100 \%$. For application of constant actinic light, the intensity of the blue LIFT LED in DC mode was calibrated using a quantum sensor (LI-190R, LI-COR, Inc.) at 0.6-m distance.

\section{Analysis of LIFT and FL3000 raw data}

For the calculation of $F_{\mathrm{v}} / F_{\mathrm{m}}$, the variable $\mathrm{ChlF}\left(F_{\mathrm{V}}\right)$ is the difference between $F_{\mathrm{m}}$ and $F_{\mathrm{o}}$. In the LIFT analysis, $F_{\mathrm{m}}$ is represented by $F_{\mathrm{m}-\mathrm{FRR}}$ as the averaged ChlF yield of $301 \mathrm{st}-302$ nd flashlet. $F_{\mathrm{o}}$ is the ChlF yield of the first flashlet (Fig. 1). In the FL3000 analysis, $F_{\mathrm{m}}$ is represented by $F_{\mathrm{m}-\mathrm{ST}}$ and measured $0.15 \mathrm{~ms}$ after the STF. $F_{\mathrm{o}}$ is measured before the STF. The $\mathrm{Q}_{\mathrm{A}}{ }^{-}$reoxidation efficiency is calculated from the $\mathrm{ChlF}$ relaxation kinetics as follows:

$$
F_{r 1,2} / F_{V}=\left(F_{V} \times t_{1,2}-\sum F_{i} \times j_{i}\right) /\left(F_{V} \times t_{1,2}\right)
$$

Here, $F_{i}$ is the ChlF yield in the relaxation phase at flashlet $i . F_{i}$ is multiplied by $j_{i}$ and summed up to represent the area of ChlF relaxation up to $t_{1}=0.65 \mathrm{~ms}\left(\right.$ for $\mathrm{F}_{\mathrm{r} 1}$ ) and $t_{2}=120 \mathrm{~ms}\left(\right.$ for $F_{\mathrm{r} 2}$ ). In case of the FL3000 data, the time points for $t_{1}$ and $t_{2}$ were $0.52 \mathrm{~ms}$ and $100 \mathrm{~ms}$ after the STF, respectively, due to different relaxation protocols. The lightadapted states of $F_{\mathrm{o}}, F_{\mathrm{m}-\mathrm{FRR}}, F_{\mathrm{v}}$, and $F_{\mathrm{r} 1,2}$ are denoted as $F^{\prime}$, $F_{\mathrm{m}-\mathrm{FRR}}{ }^{\prime}, F_{\mathrm{q}}{ }^{\prime}$, and $F_{\mathrm{r} 1,2}{ }^{\prime}$, respectively.

\section{Statistics}

Analysis of variance (ANOVA) was used to calculate significant differences $(p<0.05)$ followed by Tukey's test for pairwise comparison. Due to the small sample size $(n<7)$, normal distribution and homogeneity of variance were assumed. Analysis was done by R program using the multcomp package.

\section{Results}

Photosynthetic characteristics were studied by measuring light-induced ChlF transients using both the modulated LIFT and the double-modulated FL3000 device with an emphasis on the properties of electron transport from PSII towards PSI.

\section{Determination of $\boldsymbol{F}_{\mathrm{m}}$ levels and electron transport kinetics}

We used the $\mathrm{FRRF}_{0.75 \mathrm{~ms}}$ and $\mathrm{MTF}_{750 \mathrm{~ms}}$ protocol to study the Induction of $F_{\mathrm{m}-\mathrm{FRR}}$ and $F_{\mathrm{m}-\mathrm{MT}}$, respectively (Table 1$)$. The $F_{\mathrm{m}-\mathrm{FRR}}$ in control leaves was significantly lower than $F_{\mathrm{m}-\mathrm{MT}}$ (Figs. 1, 2a, b). Under control conditions, $F_{\mathrm{m}-\mathrm{FRR}}$ saturated earliest at about $0.25 \mathrm{~ms}$ depending on the excitation power (Fig. S1). At the end of the induction phase, a small peak of ChlF occurs pointing towards a minor ChlF quenching during the high excitation power of the $\mathrm{FRRF}_{0.75 \mathrm{~ms}}$. These spikes contributed to $F_{\mathrm{m}-\mathrm{FRR}}$ resulting in $F_{\mathrm{v}} / F_{\mathrm{m}}$ values independent of the excitation power. In contrast, $F_{\mathrm{m}-\mathrm{MT}}$ in intact leaves was reached after $750 \mathrm{~ms}$ and showed the same $F_{\mathrm{m}-\mathrm{MT}}$ as in the presence of DCMU (Fig. 2b).

We studied ChlF relaxation on attached leaves in the dark by using $\mathrm{FRRF}_{0.75 \mathrm{~ms}}$ under control and $\mathrm{N}_{2}$ atmosphere. The absence of $\mathrm{O}_{2}$ in the latter condition prevents reoxidation of the PQ pool in the dark (Tóth et al. 2007b). After 5 min in the $\mathrm{N}_{2}$ atmosphere, ChlF relaxation phase was significantly altered compared to control conditions (Fig. 2a). While $F_{\mathrm{v}} / F_{\mathrm{m}}$ did not change under control and $\mathrm{N}_{2}$ atmosphere, $F_{\mathrm{r} 1} / F_{\mathrm{v}}$ in the $\mathrm{N}_{2}$ atmosphere decreased significantly to $0.16( \pm 0.01)$ compared to $0.18( \pm 0.01)$ in the control (Fig. 3). In contrast, $F_{\mathrm{r} 2} / F_{\mathrm{v}}$ was significantly increased in the $\mathrm{N}_{2}$ atmosphere compared to the control. Notably, also the ChlF induction phase of $\mathrm{MTF}_{750 \mathrm{~ms}}$ differed in $\mathrm{N}_{2}$ atmosphere compared to control (Fig. 2b). Following $\mathrm{MTF}_{750 \mathrm{~ms}}$, we kept the plants for additional 5 min under the control or $\mathrm{N}_{2}$ atmosphere. This allowed S-states of the OEC to relax in the dark (Kolber et al. 1998), whereas the PQ pool remained reduced in the $\mathrm{N}_{2}$ atmosphere. Then a subsequent measurement using $\mathrm{FRRF}_{2.5 \mathrm{~ms}}$ was initiated. $F_{\mathrm{m}-\mathrm{FRR}}$ in the control 


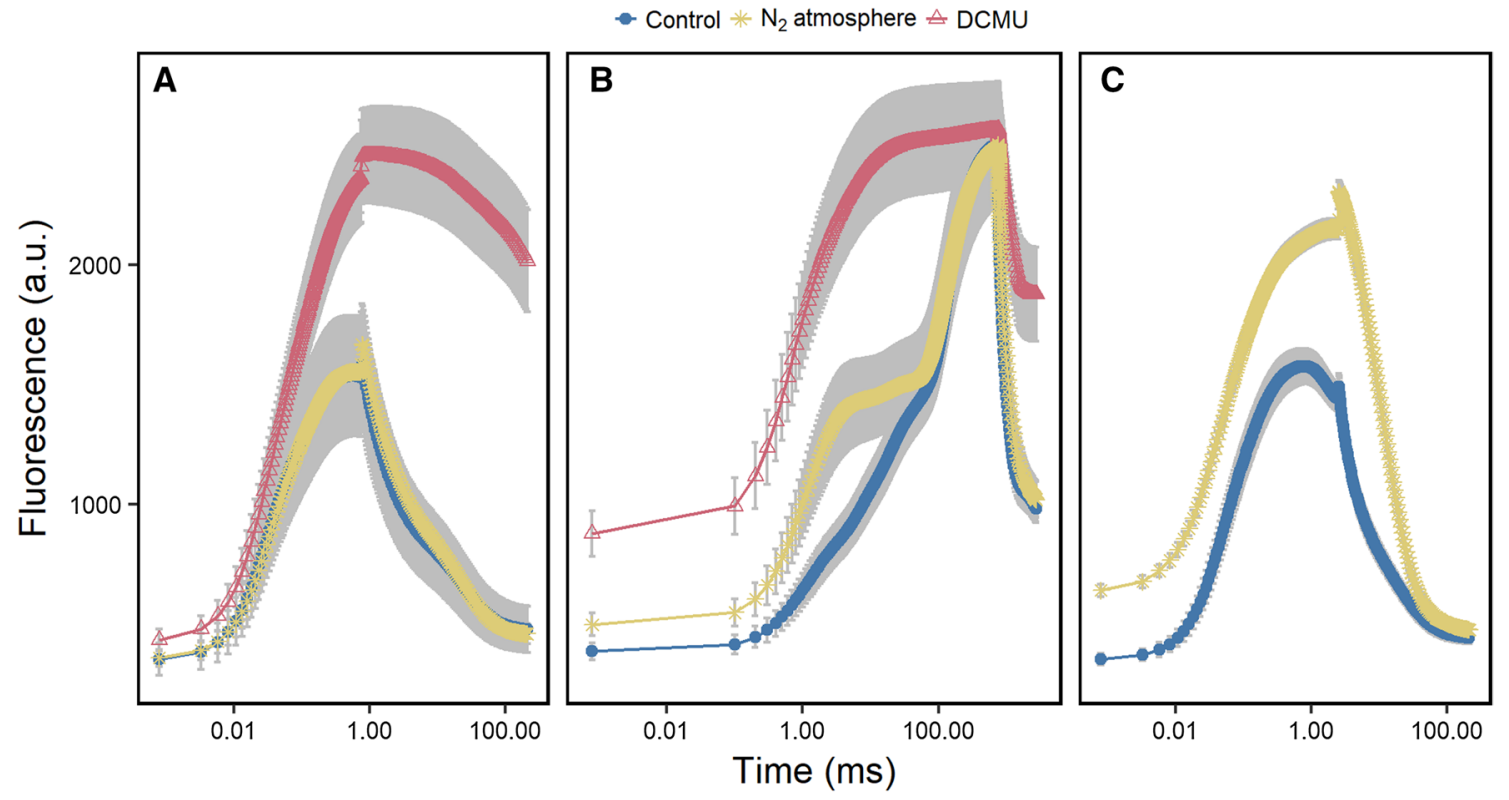

Fig. 2 Dark-adapted spinach leaves were subjected to a 3-(3,4-dichlorophenyl)-1,1-dimethylurea (DCMU) treatment and nitrogen $\left(\mathrm{N}_{2}\right)$ atmosphere, which prevent reoxidation of the primary quinone acceptor $\left(\mathrm{Q}_{\mathrm{A}}\right)$, and plastoquinone (PQ) pool in the dark, respectively. Under those treatments, fast repetition rate flash for $0.75 \mathrm{~ms}\left(\mathrm{FRRF}_{0.75 \mathrm{~ms}}, \mathbf{a}\right)$, multiple turnover flash $\left(\mathrm{MTF}_{750 \mathrm{~ms}}, \mathbf{b}\right)$, and fast repetition rate flash for $2.5 \mathrm{~ms}\left(\mathrm{FRRF}_{2.5 \mathrm{~ms}}, \mathbf{c}\right)$ were used to study chlorophyll fluorescence induction and relaxation. $\mathrm{FRRF}_{0.75 \mathrm{~ms}}$ was performed after $5 \mathrm{~min}$ in control or $\mathrm{N}_{2}$ atmosphere (for DCMU treatment see "Materials and methods" section). $\mathrm{MTF}_{750 \mathrm{~ms}}$ was performed after $\mathrm{FRRF}_{0.75 \mathrm{~ms}} . \mathrm{FRRF}_{2.5 \mathrm{~ms}}$ was performed after additional $5 \mathrm{~min}$ in control or $\mathrm{N}_{2}$ atmosphere. Chlorophyll fluorescence transients are presented on a logarithmic time scale. Error bars showing standard deviation of the mean ( $n=6$ plants) treatment was reached at around $750 \mu$ s and then the $\mathrm{ChlF}$ signal started to decline (Fig. 2c). In the $\mathrm{N}_{2}$ atmosphere, the $\mathrm{ChlF}$ level continued to increase during the $\mathrm{FRRF}_{2.5 \mathrm{~ms}}$ without reaching saturation. This resulted in a significantly increased $F_{\mathrm{m}-\mathrm{FRR}}$ relative to the control. In addition, $F_{\mathrm{o}}$ levels were higher in the $\mathrm{N}_{2}$ atmosphere compared to control in the subsequent flashes (Fig. 2b, c). This led to significantly lowered $F_{\mathrm{v}} / F_{\mathrm{m}}$ under $\mathrm{N}_{2}$ atmosphere using $\mathrm{FRRF}_{2.5 \mathrm{~ms}}$ ( $p$ value $<0.001$ ). In summary, $F_{\mathrm{m}-\mathrm{MT}}$ induction in untreated leaves using $\mathrm{MTF}_{750 \mathrm{~ms}}$ was confirmed by the same $F_{\mathrm{m}}$ induced in DCMU-treated leaves. Full saturation of $F_{\mathrm{m}-\mathrm{FRR}}$ level was confirmed using $\mathrm{FRRF}_{2.5 \mathrm{~ms}}$ under two conditions: (1) plants were in controlled, aerobic conditions (PQ pool was oxidized); and (2) the leaf was fully darkadapted (OEC mainly in the $\mathrm{S}_{1}$-state) (Delosme and Joliot 2002). The influence of increased PQ pool reduction was reflected in decreased $F_{\mathrm{rl}} / F_{\mathrm{v}}$, and increased $F_{\mathrm{o}}$ and $F_{\mathrm{m}-\mathrm{FRR}}$.

\section{Comparison of electron transport kinetics measured by the LIFT and FL3000 device}

We compared the ChlF relaxation kinetics acquired by the modulated LIFT to those of the double-modulated FL3000 device. For that purpose, we treated the thylakoids with different electron transport inhibitors. The two methods resulted in similar ChlF relaxation curves (Fig. 4). The
$F_{\mathrm{v}} / F_{\mathrm{m}}$ values calculated from the LIFT measurements ranged between $0.58( \pm 0.01)$ for BBY and $0.7( \pm 0.02)$ for thylakoids (Fig. 5a). The FL3000 device showed generally lower $F_{\mathrm{v}} / F_{\mathrm{m}}$ values: $0.31( \pm 0.04)$ for BBY particles and $0.49( \pm 0.02)$ for thylakoids (Fig. 5b). In BBY particles, electron transport is impaired after the $\mathrm{Q}_{B}$ site since the PQ pool is partly, and the PSI fully removed (Berthold et al. 1981). DBMIB binds to the cytb ${ }_{6}$ complex, which blocks the reoxidation of the PQ pool (Bohme et al. 1971). Consequently, BBYs and DBMIB-treated thylakoids showed slower ChlF relaxation kinetics compared to thylakoids, resulting in significantly lower $F_{\mathrm{r} 1} / F_{\mathrm{v}}$ and $F_{\mathrm{r} 2} / F_{\mathrm{v}}$ values in both methods (Fig. $5 \mathrm{c}-\mathrm{f}$ ). $F_{\mathrm{r} 1} / F_{\mathrm{v}}$ for the LIFT device ranged from $0.21( \pm 0.008)$ for thylakoids to 0.04 $( \pm 0.008)$ for BBY (Fig. 5c). The $F_{\mathrm{r} 1} / F_{\mathrm{v}}$ values calculated from the FL3000 measurements were in general higher (e.g., $0.34( \pm 0.025)$ for thylakoids and $0.1( \pm 0.013)$ for BBY, Fig. 5d) but showed the same tendency as in the LIFT measurements. $F_{\mathrm{r} 2} / F_{\mathrm{v}}$ showed increasing difference between the control and treated samples reflecting impaired electron transport (Fig. 5e, f). In summary, $F_{\mathrm{r} 1} / F_{\mathrm{v}}$ and $F_{\mathrm{r} 2} / F_{\mathrm{v}}$ measured with both devices responded specifically to the treatments which block electron transport at different steps. 


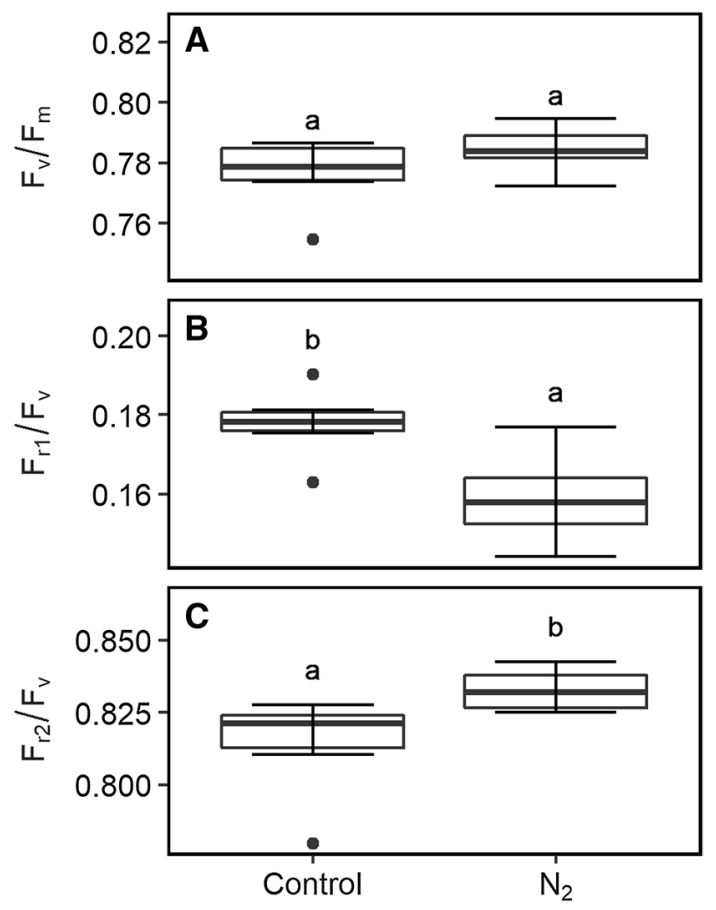

Fig. 3 Boxplot of quantum efficiency of the photosystem II $\left(F_{\mathrm{v}} / F_{\mathrm{m}}\right.$, a), efficiency of primary quinone acceptor $\left(\mathrm{Q}_{\mathrm{A}}\right)$ reoxidation in $0.65 \mathrm{~ms}\left(F_{\mathrm{r} 1} / F_{\mathrm{v}}, \mathbf{b}\right)$, and $120 \mathrm{~ms}\left(F_{\mathrm{r} 2} / F_{\mathrm{v}}, \mathbf{c}\right)$ relaxation phases of darkadapted attached spinach leaves are shown. Measurements took place 5 min after exposure to control or nitrogen $\left(\mathrm{N}_{2}\right)$ atmosphere. Parameters were obtained using fast repetition rate flash $\left(\mathrm{FRRF}_{0.75 \mathrm{~ms}}\right)$ of the light-induced fluorescence transient (LIFT) instrument. Box represents inter-quartile range, bold horizontal bar the median, the discontinuous lines the upper and lower quartile, and outlier data points $(>1.5 \times$ inter-quartile range) are depicted by a point ( $n=6$ plants). Boxes labeled with different letters differ significantly from each other according to Tukey's multiple comparisons of means

\section{Electron transport kinetics measured under ambient light}

We measured light-response curves on attached spinach leaves in order to follow the light saturation of electron transport rate. $\mathrm{F}^{\prime}$ initially increased with increasing light intensities, but this increase was then reversed, most likely due to NPQ formation (Fig. 6a). Simultaneously, $F_{\mathrm{m}-\mathrm{FRR}}{ }^{\prime}$ decreased in response to increasing light intensities due to NPQ formation. $F_{\mathrm{m}-\mathrm{FRR}}$ ' showed smaller absolute differences than $F_{\mathrm{m}-\mathrm{MT}}$ ' compared to the corresponding darkadapted states (Fig. 6b).

The $F_{\mathrm{q}}{ }^{\prime} / F_{\mathrm{m}}{ }^{\prime}$ values we obtained with the $\mathrm{FRRF}_{0.75 \mathrm{~ms}}$ protocol correlated highly with $F_{\mathrm{q}}{ }^{\prime} / F_{\mathrm{m}}{ }^{\prime}$ values we retrieved with the $\mathrm{MTF}_{750 \mathrm{~ms}}$ protocol $\left(r^{2}=0.99\right)$ during the measurements of blue-light response curves (Fig. 7). This demonstrates that $\mathrm{FRRF}_{0.75 \mathrm{~ms}}$ and $\mathrm{MTF}_{750 \mathrm{~ms}}$ measurements result in basically the same parameters with the exception of an offset, at least under these standard conditions. Increasing light intensities resulted in a significant decrease in the $F_{\mathrm{q}}{ }^{\prime} / F_{\mathrm{m}}{ }^{\prime}($ Fig. 8a). In

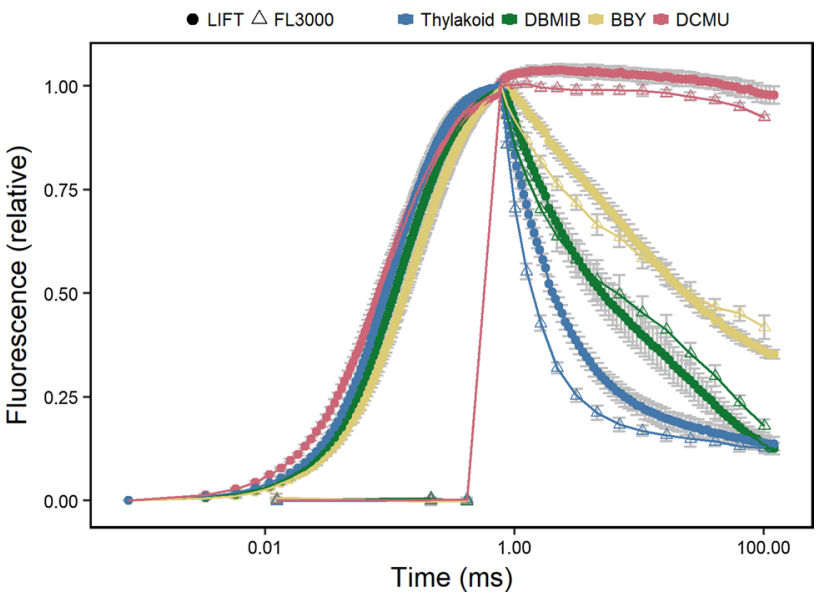

Fig. 4 Chlorophyll fluorescence transients of isolated spinach thylakoids and photosystem II particles (BBY) are presented on a logarithmic time scale. The measurements were performed either by the light-induced fluorescence transient (LIFT) device (closed circles) or with the double-modulated FL3000 fluorometer (open triangles). Thylakoid samples $(10 \mu \mathrm{g}$ chlorophyll $/ \mathrm{mL})$ were either untreated, or treated with $5 \mu \mathrm{M} 3-(3,4-$ dichlorophenyl)-1,1-dimethylurea (DCMU) or $\quad 0.66 \quad \mu \mathrm{M}$ 2,5-dibromo-5-methyl-6-isopropyl-benzoquinone (DBMIB). Chlorophyll fluorescence signals are double normalized so that the signal starts from 0 for measured minimum fluorescence $\left(F_{\mathrm{o}}\right)$, and has a total amplitude of 1 . Chemicals were added in the dark and samples were dark-adapted for $3 \mathrm{~min}$ before measurement. Error bars show standard deviation ( $n=5$, except DCMU FL3000 and DBMIB FL3000 $n=3$ )

contrast, $F_{\mathrm{r} 1}{ }^{\prime} / F_{\mathrm{q}}{ }^{\prime}$ and $F_{\mathrm{r} 2}{ }^{\prime} / F_{\mathrm{q}}{ }^{\prime}$ were less affected by the higher light intensities (Fig. 8b, c). Upon dark to light transition at $30 \mu \mathrm{mol}$ photons $\mathrm{m}^{-2} \mathrm{~s}^{-1}, F_{\mathrm{r} 1}{ }^{\prime} / F_{\mathrm{q}}{ }^{\prime}$ decreased from 0.18 $( \pm 0.009)$ to $0.10( \pm 0.023)$ and increased to $0.2( \pm 0.01)$ at the last two light intensities. $F_{\mathrm{r} 2}{ }^{\prime} / F_{\mathrm{q}}{ }^{\prime}$ increased from 0.81 $( \pm 0.018)$ to $0.95( \pm 0.035)$ and then was stabilized at 0.89 $( \pm 0.02)$ at the higher light intensities. $F_{\mathrm{r} 1}{ }^{\prime} / F_{\mathrm{q}}{ }^{\prime}$ measured in the light was not significantly different from dark-adapted values, with the exception of the initial light step at $30 \mu \mathrm{mol}$ photons $\mathrm{m}^{-2} \mathrm{~s}^{-1}$. In summary, ChlF relaxation kinetics in the light were little affected by increasing light intensities and NPQ, whereas $F_{\mathrm{q}}{ }^{\prime} / F_{\mathrm{m}}{ }^{\prime}$ decreased.

\section{Discussion}

We induced ChlF transients by using different LIFT-FRR excitation protocols $\left(\mathrm{FRRF}_{0.75 \mathrm{~ms}}\right.$ and $\left.\mathrm{MTF}_{750 \mathrm{~ms}}\right)$ at $0.6 \mathrm{~m}$ distance (Fig. 1). $F_{\mathrm{v}} / F_{\mathrm{m}}$ and $F_{\mathrm{q}}{ }^{\prime} / F_{\mathrm{m}}{ }^{\prime}$ were highly correlated between the two protocols (Fig. 7). Furthermore, we characterized a range of photo-physiological properties with an emphasis on the kinetics of electron transport from PSII towards PSI. These kinetics are determined by the wellestablished architecture of photosynthetic linear electron transport chain and can be observed via ChlF relaxation 


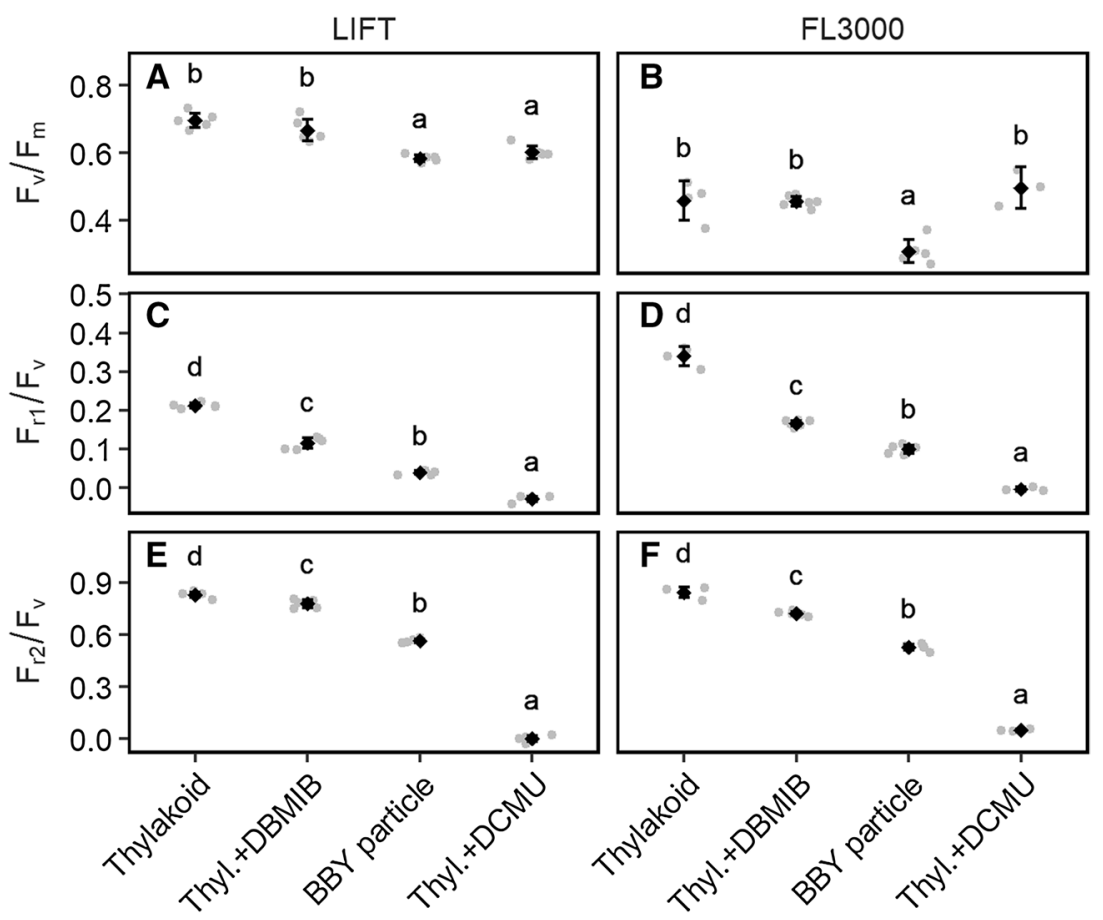

Fig. 5 Comparison of photosystem II quantum efficiency $\left(F_{\mathrm{v}} / F_{\mathrm{m}}, \mathbf{a}\right.$, b) and efficiency of primary quinone acceptor $\left(\mathrm{Q}_{\mathrm{A}}\right)$ reoxidation in $0.65 \mathrm{~ms}\left(F_{\mathrm{r} 1} / F_{\mathrm{v}}, \mathbf{c}, \mathbf{d}\right)$, and $120 \mathrm{~ms}\left(F_{\mathrm{r} 2} / F_{\mathrm{v}}, \mathbf{e}, \mathbf{f}\right)$ relaxation phases in dark-adapted state acquired by light-induced fluorescence transient (LIFT) and double-modulated FL3000 fluorometer. Measurements were carried out on isolated spinach thylakoids and BBY particles. Thylakoid samples $(10 \mu \mathrm{g}$ chlorophyll/mL) were either untreated or treated with $5 \mu \mathrm{M} 3$-(3,4-dichlorophenyl)-1,1-dimethylurea (DCMU) or $0.66 \mu \mathrm{M} \quad$ 2,5-dibromo-5-methyl-6-isopropyl-benzoquinone (DBMIB), resulting in different chlorophyll fluorescence relaxations as shown in Fig. 4. Black diamonds show mean values and error bars indicate the $95 \%$ confidence intervals. Individual data points are depicted by a grey point ( $n=5$, except DCMU FL3000 and DBMIB FL3000 $n=3$ ). Means labeled with different letters differ significantly from each other according to Tukey's multiple comparisons of means
Fig. 6 Chlorophyll fluorescence response of attached spinach leaves measured under different intensities of background irradiance by the light-induced fluorescence transient (LIFT) instrument. Leaves were exposed to 0 (dark-adapted), 30, 100, 300, and $700 \mu \mathrm{mol}$ photons $\mathrm{m}^{-2} \mathrm{~s}^{-1}$ blue light $(445 \mathrm{~nm})$. Fast repetition rate flash $\left(\mathrm{FRRF}_{0.75 \mathrm{~ms}}, \mathbf{a}\right)$ and multiple turnover flash $\left(\mathrm{MTF}_{750 \mathrm{~ms}} ; \mathbf{b}\right)$ were performed on dark-adapted samples and after reaching the steady state at each light intensity (after $3 \mathrm{~min}$ ). Chlorophyll fluorescence transients are presented on a logarithmic time scale. Error bars show the standard error of the mean ( $n=6$ plants)

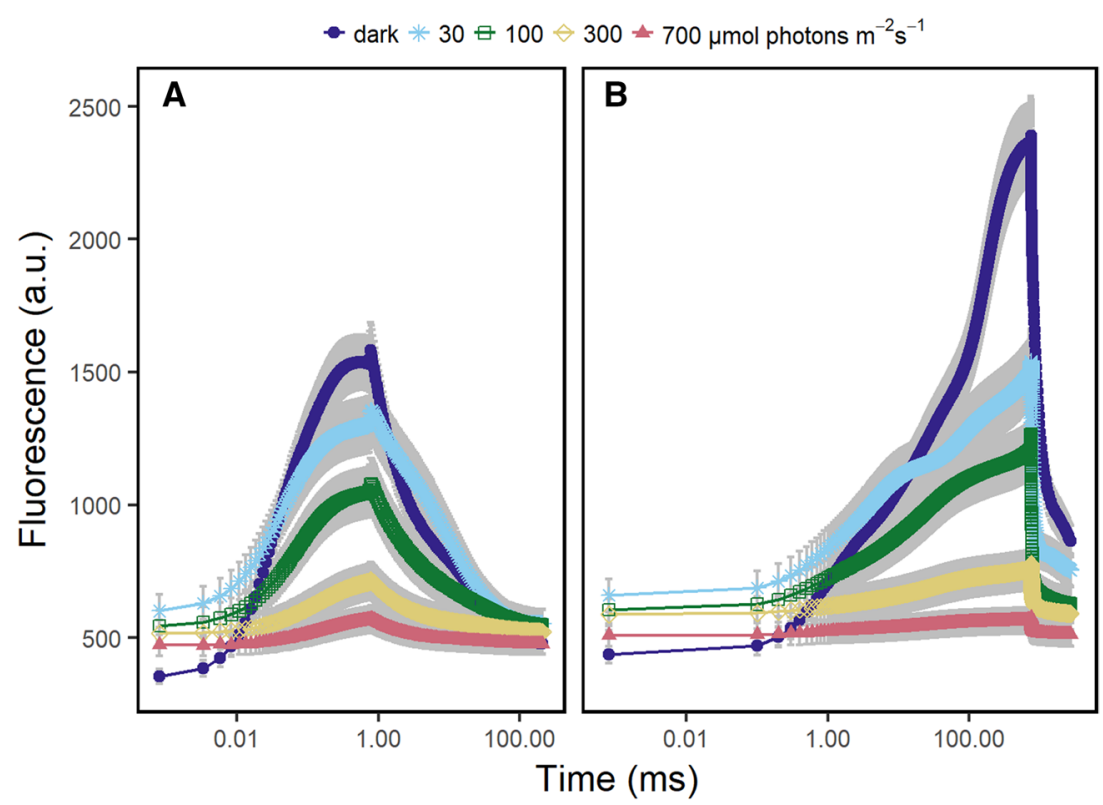

reflecting the kinetics of $\mathrm{Q}_{\mathrm{A}}{ }^{-}$reoxidation (Vass et al. 1999). Efficiency of $\mathrm{Q}_{\mathrm{A}}{ }^{-}$reoxidation was assessed in $0.65 \mathrm{~ms}$ and $120 \mathrm{~ms}$ relaxation phases after the FRR excitation, expressed in the $F_{\mathrm{r} 1} / F_{\mathrm{v}}$ and $F_{\mathrm{r} 2} / F_{\mathrm{v}}$ parameter, respectively. These simple parameters reflect the overall reoxidation of $\mathrm{Q}_{\mathrm{A}}{ }^{-}$during the indicated time periods. In the light, $F_{\mathrm{r} 2}{ }^{\prime} / F$ reflected 


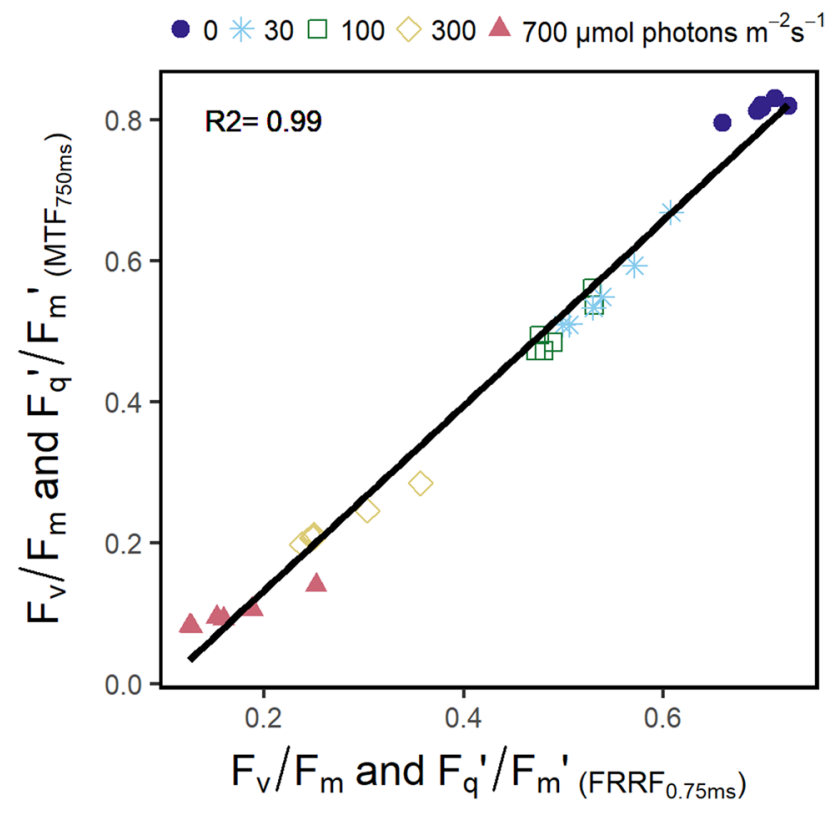

Fig. 7 Correlation of quantum efficiency of the photosystem II in the dark-adapted state $\left(F_{\mathrm{v}} / F_{\mathrm{m}}\right)$ and the light-adapted state $\left(F_{\mathrm{q}}{ }^{\prime} / F_{\mathrm{m}}{ }^{\prime}\right)$ obtained by fast repetition rate flash $\left(\mathrm{FRRF}_{0.75 \mathrm{~ms}}\right)$ and multiple turnover flash $\left(\mathrm{MTF}_{750 \mathrm{~ms}}\right)$ during a blue-light response curve of spinach leaves. Maximum fluorescence ( $F_{\mathrm{m}}$ in the dark and $F_{\mathrm{m}}{ }^{\prime}$ in the light) represents chlorophyll fluorescence yield of the averaged 300th and 301 st flashlet of the $\mathrm{FRRF}_{0.75 \mathrm{~ms}}$ respective the yield of the 7500th flashlet in case of the $\mathrm{MTF}_{750 \mathrm{~ms}}$. Variable fluorescence $\left(F_{\mathrm{v}}\right.$ in the dark or $F_{\mathrm{q}}{ }^{\prime}$ in the light) is the difference between $F_{\mathrm{m}}$ or $F_{\mathrm{m}}{ }^{\prime}$ and the chlorophyll fluorescence yield of the first flashlet $\left(F_{\mathrm{o}}\right.$ in the dark or $F^{\prime}$ in the light). The regression formula was $y=-0.13+1.31 \times x$. Measurements were performed using the light-induced fluorescence transient (LIFT) device ( $n=6$ plants)

electron transport capacity from $\mathrm{Q}_{\mathrm{A}}$ towards PSI and was far less sensitive to increasing light intensities than $F^{\prime} / F_{\mathrm{m}}{ }^{\prime}$ (Fig. 8). The results provide additional information about electron transport, which are not reflected by the $F_{\mathrm{v}} / F_{\mathrm{m}}$ parameter.

\section{Maximum fluorescence}

We demonstrated ChlF induction at $0.6 \mathrm{~m}$ distance by using the LIFT instrument on attached spinach leaves. $F_{\text {m-MT }}$ in the control leaves was reached at $750 \mathrm{~ms}$ after multiple turnover of PSII reaction centers (Fig. 2b). That $F_{\text {m-MT }}$ was indeed saturated by using $\mathrm{MTF}_{750 \mathrm{~ms}}$, was confirmed by using the DCMU treatment, which showed the same ChlF level. DCMU inhibits $\mathrm{Q}_{\mathrm{A}}{ }^{-}$reoxidation and induces $F_{\mathrm{m}-\mathrm{MT}}$ in intact leaves (Tóth et al. 2005). In contrast to $F_{\mathrm{m}-\mathrm{MT}}, F_{\mathrm{m}-\mathrm{ST}}$ is reached within 40 to 60 $\mu$ within one full turnover of the PSII reaction centers (Kolber et al. 1998; Nedbal et al. 1999; Belyaeva et al. 2014). The level of $F_{\mathrm{m}-\mathrm{ST}}$ is about 50\% lower compared to $F_{\mathrm{m}-\mathrm{MT}}$ and is based on fully reduced $\mathrm{Q}_{\mathrm{A}}$ (e.g., Samson
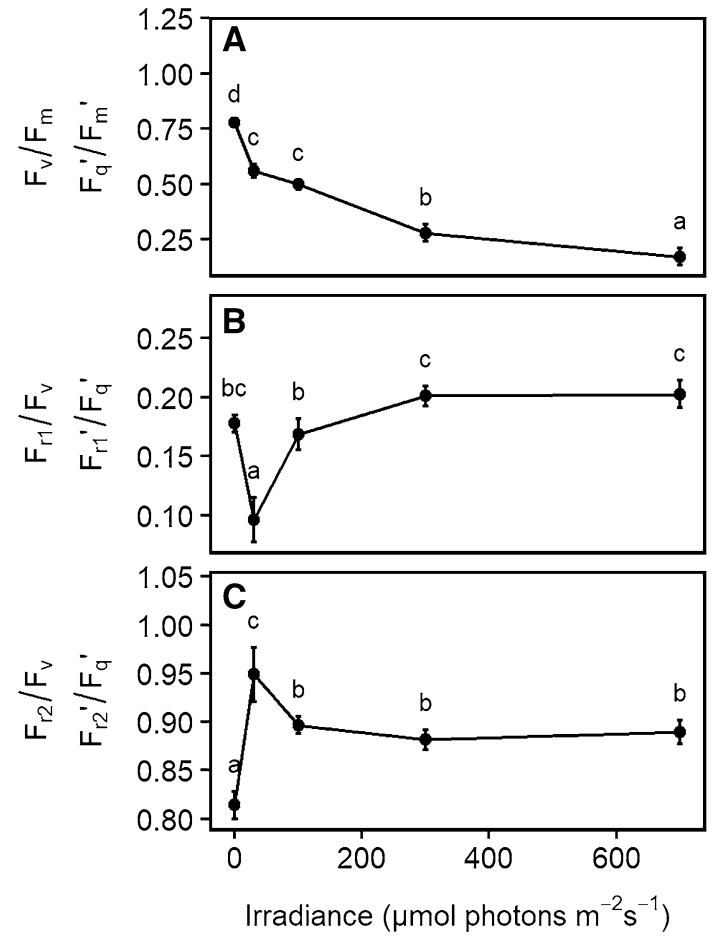

Fig. 8 Quantum efficiency of the photosystem II $\left(F_{\mathrm{v}} / F_{\mathrm{m}}\right.$ in the dark, and $F_{\mathrm{q}}{ }^{\prime} / F_{\mathrm{m}}{ }^{\prime}$ in the light, a) and efficiency of primary quinone acceptor $\left(\mathrm{Q}_{\mathrm{A}}\right)$ reoxidation in $0.65 \mathrm{~ms}\left(F_{\mathrm{rl}} / F_{\mathrm{v}}\right.$ in the dark, and $F_{\mathrm{r} 1}{ }^{\prime} / F_{\mathrm{q}}{ }^{\prime}$ in the light, $\mathbf{b}$,$) and 120 \mathrm{~ms}\left(F_{\mathrm{r} 2} / F_{\mathrm{v}}\right.$ in the dark, and $F_{\mathrm{r} 2}{ }^{\prime} / F_{\mathrm{q}}{ }^{\prime}$ in the light, c) relaxation phases of attached spinach leaves were measured under different intensities of background irradiance. Parameters were acquired using fast repetition rate flash $\left(\mathrm{FRRF}_{0.75 \mathrm{~ms}}\right)$ of the light-induced fluorescence transient (LIFT) instrument. Black dots show mean values and error bars indicate the 95\% confident interval ( $n=6$ plants). Means labeled with different letters differ significantly from each other according to Tukey's multiple comparisons of means

and Bruce 1996; Schansker et al. 2014). The difference between $F_{-\mathrm{MT}}$ and $F_{\mathrm{m}-\mathrm{ST}}$ is suggested to be caused by additional ChlF quenchers that are removed during multiple turnovers (Delosme 1967; Kalaji et al. 2017). In this study, the $F_{\mathrm{m}-\mathrm{FRR}}$ induced by $\mathrm{FRRF}_{0.75 \mathrm{~ms}}$ saturated at about $0.25 \mathrm{~ms}$ at highest excitation power of $40,000 \mu \mathrm{mol}$ photons $\mathrm{m}^{-2} \mathrm{~s}^{-1}$ (Fig. S1). Within this time range, the OEC is already in the second turnover and $\mathrm{Q}_{\mathrm{A}}{ }^{-}$is once reoxidized by $\mathrm{Q}_{\mathrm{B}}$ (Ananyev and Dismukes 2005b; PérezNavarro et al. 2016). The reoxidation of $\mathrm{Q}_{\mathrm{A}}{ }^{-}$by $\mathrm{Q}_{B}$ and $\mathrm{Q}_{\mathrm{B}}{ }^{-}$has time constants of $0.2 \mathrm{~ms}$ and $0.7 \mathrm{~ms}$, respectively (Bowes and Crofts 1980; de Wijn and van Gorkom 2001; Tomek et al. 2001). The second time constants may vary with respect to the kinetics of $\mathrm{H}^{+}$uptake by $\mathrm{Q}_{\mathrm{B}}{ }^{-}$(Petrouleas and Crofts 2005). The saturating behavior of $F_{\mathrm{m}-\mathrm{FRR}}$ strongly indicates that photochemical processes stabilized within the $\mathrm{FRRF}_{0.75 \mathrm{~ms}}$ (Fig. S1). In agreement, the derived $F_{\mathrm{v}} / F_{\mathrm{m}}$ values were independent from the used excitation power. We conclude that $F_{\mathrm{m}-\mathrm{FRR}}$ reflected fully reduced $\mathrm{Q}_{\mathrm{A}}$ mainly associated with $\mathrm{Q}_{\mathrm{B}}{ }^{-}$. 
Using the FRRF $2.5 \mathrm{~ms}$ protocol, $F_{\mathrm{m}-\mathrm{FRR}}$ declined after reaching a plateau under control conditions (Fig. 2c). This behavior was only observed when the PQ pool was oxidized and the sample was dark-adapted. Similarly, the polyphasic ChlF rise during a MTF of $15,000 \mu \mathrm{mol}$ photons $\mathrm{m}^{-2} \mathrm{~s}^{-1}$ records a local ChlF maximum at about $2 \mathrm{~ms}$ (J-step) (Schreiber 1986a; Tóth et al. 2007a; Schansker et al. 2011). This ChlF peak appears only when the sample is in the $\mathrm{S}_{1}$-state, i.e., dark-adapted (Strasser 1997). In the ChlF decline, $\mathrm{Q}_{\mathrm{A}}$ reduction is overcome by $\mathrm{Q}_{\mathrm{A}}{ }^{-}$reoxidation via the oxidized PSII primary donor $\left(\mathrm{P} 680^{+}\right)$, which accumulates during the slow $\mathrm{S}_{3}-\mathrm{S}_{4}$ transition of the OEC (Schansker et al. 2011; Kalaji et al. 2017). The phase of ChlF decline matches time wise with the formation of $\mathrm{Q}_{\mathrm{B}}{ }^{2-}$ (Bowes and Crofts 1980; de Wijn and van Gorkom 2001). After 2 ms, electron delivery of the OEC proceeds and re-reduction of $\mathrm{Q}_{\mathrm{A}}$, further accumulation of $\mathrm{Q}_{\mathrm{B}}{ }^{2-}$ and exchange of $\mathrm{Q}_{\mathrm{B}}{ }^{2-}$ by an oxidized PQ takes place (Petrouleas and Crofts 2005). These processes lead to an increasing ChlF signal during a MTF, known as thermal phase (Delosme 1967; Lazár 2006). It was shown before that $\mathrm{PQ}$ pool reduction leads to a higher ChlF signal by releasing non-photochemically quenched ChlF (Vernotte et al. 1979; Haldimann and Tsimilli-Michael 2005). In agreement, $F_{\mathrm{m}-\mathrm{FRR}}$ increased without reaching saturation when the PQ pool was already reduced in the dark (Fig. 2c). Similarly, $F_{\mathrm{o}}$ under $\mathrm{N}_{2}$ atmosphere was also higher than in the control but was the same in the subsequent $\mathrm{FRRF}_{2.5 \mathrm{~ms}}$ ( $p$ value $=0.403$, data not shown $)$ due to reoxidation of PQ pool during the flash. $F_{\mathrm{o}}$ yield was shown to be dependent on PQ redox state and can be recovered by farred light pulse (Diner 1977; Hohmann-Marriott et al. 2010; Kalaji et al. 2017). However, this additional ChlF quenching is probably not directly controlled by the PQ pool (Tóth et al. 2005). It may be induced by the occupancy of the $\mathrm{Q}_{\mathrm{B}}$-pocket or by conformational changes in the PSII complex (Falkowski et al. 2004; Schansker et al. 2014; Magyar et al. 2018; Prášil et al. 2018). This might explain that $F_{\mathrm{m}-\mathrm{ST}}$ (when only $\mathrm{Q}_{\mathrm{A}}$ is reduced) cannot surpass the ChlF level at the J-step (Schreiber 1986a). Another reason for the lower $F_{\text {m-ST }}$ compared to the J-step might be that STF induced a quenching mechanism during the reduction phase of $\mathrm{Q}_{\mathrm{A}}$. At the end of the $\mathrm{FRRF}_{0.75 \mathrm{~ms}}$ induction phase, when changing from fast to low repetition rate flashlets, we noticed an instantaneous ChlF spike (Fig. S1). This indicates a fastrelaxing quenching mechanism. It was suggested earlier that carotenoid triplets quench ChlF within $\mu$ s when operating with flashes at high excitation power (Schödel et al. 1999; Steffen et al. 2001; Braslavsky and Holzwarth 2012; Belyaeva et al. 2014). In summary, saturated $F_{\mathrm{m}-\mathrm{FRR}}$ differs from $F_{\mathrm{m}-\mathrm{ST}}$ in the reduction of $\mathrm{Q}_{\mathrm{B}}$ to $\mathrm{Q}_{\mathrm{B}}{ }^{-}$while $\mathrm{Q}_{\mathrm{A}}$ is fully rereduced. $F_{\mathrm{m}-\mathrm{FRR}}$ and $F_{\mathrm{m}-\mathrm{ST}}$ are expected to be comparable since $\mathrm{Q}_{\mathrm{B}}{ }^{-}$is not known to quench any $\mathrm{ChlF}$ (Schansker et al. 2011). The saturation of $F_{\mathrm{m}-\mathrm{FRR}}$ after $0.25 \mathrm{~ms}$ indicates that
$\mathrm{Q}_{\mathrm{B}}{ }^{2-}$ was not formed. The $F_{\mathrm{m}-\mathrm{FRR}}$ differs from the J-step in the redox state of the OEC and the accumulation of $\mathrm{Q}_{\mathrm{B}}{ }^{2-}$ which influence ChlF (see also Osmond et al. 2017). When reaching $F_{\mathrm{m}-\mathrm{MT}}$, at least one additional quencher is removed increasing ChlF signal by a still unclear mechanism (Magyar et al. 2018; Prášil et al. 2018).

\section{Validation of electron transport kinetics}

Anaerobiosis inhibits PQ pool reoxidation in the dark (Bohme et al. 1971; Cournac et al. 2000; Feilke et al. 2014). As expected, reduced $\mathrm{PQ}$ pool under $\mathrm{N}_{2}$ atmosphere affected ChlF relaxation and decreased $F_{\mathrm{rl}} / F_{\mathrm{v}}$ compared to control (Fig. 3b). ChlF relaxation was compared between the modulated LIFT-FRR and the double-modulated FL3000 device. The two devices measured similar qualitative responses comparable to earlier studies (Deák et al. 2014). However, $\mathrm{Q}_{\mathrm{A}}{ }^{-}$reoxidation was faster in the first milliseconds when measuring with the double-modulated FL3000 than the LIFT device (Fig. 4). This might be due to the shorter duration of the STF than $\mathrm{FRRF}_{0.75 \mathrm{~ms}}$, where the latter reduced $\mathrm{Q}_{\mathrm{B}}$ already. In addition, the FRR flashlets have an actinic effect, which partially reduce $\mathrm{Q}_{\mathrm{A}}$ and slow down the $\mathrm{Q}_{\mathrm{A}}{ }^{-}$reoxidation kinetics. The STF of the FL3000 device with $1000 \mu \mathrm{mol}$ photons $\mathrm{m}^{-2} \mathrm{~s}^{-1}$ was probably not saturating resulting in the lower $F_{\mathrm{v}} / F_{\mathrm{m}}$ values compared to the values derived by the LIFT device. In summary, a wide range of impaired electron transport processes were detected using the ChlF relaxation parameters $F_{\mathrm{r} 1} / F_{\mathrm{v}}$ and $F_{\mathrm{r} 2} / F_{\mathrm{v}}$ derived either by the LIFT or the FL3000 device.

\section{Measurements in the light and effect on electron transport kinetics}

In the dark, the $F_{\mathrm{m}-\mathrm{FRR}}$ yield was linked to PQ redox state and S-state of the OEC. The situation is different in the light because NPQ occurs and S-states are randomized. $F_{\mathrm{m}-\mathrm{FRR}}{ }^{\prime}$ was interpreted as equilibrium of $\mathrm{Q}_{\mathrm{A}}$ reduction, NPQ and subsequent $\mathrm{Q}_{\mathrm{A}}{ }^{-}$reoxidation (Fig. 6a, Osmond et al. 2017). Accordingly, $F_{\mathrm{m}-\mathrm{MT}}$ in the light does not reach saturation because NPQ limits light harvesting and electron transport quenches ChlF very efficiently (Loriaux et al. 2013). The $\mathrm{MTF}_{750 \mathrm{~ms}}$ with rather low excitation power $(1000 \mu \mathrm{mol}$ photons $\mathrm{m}^{-2} \mathrm{~s}^{-1}$ ) limited $F_{\mathrm{m}-\mathrm{MT}}$ ' saturation additionally. However, $F_{\mathrm{q}}{ }^{\prime} / F_{\mathrm{m}}{ }^{\prime}$ derived by $\mathrm{FRRF}_{0.75 \mathrm{~ms}}$ during the measurement of blue-light response curve correlated highly with $F_{\mathrm{q}}{ }^{\prime} / F_{\mathrm{m}}{ }^{\prime}$ derived by $\mathrm{MTF}_{750 \mathrm{~ms}}\left(R^{2}=0.99\right)$ (Fig. 7). Correspondingly, $F_{\mathrm{q}}{ }^{\prime} / F_{\mathrm{m}}{ }^{\prime}$ derived with a previous LIFT device using FRR flashes was shown to be well-correlated to the values measured by a PAM device $\left(R^{2}=0.89\right)$ (Pieruschka et al. 2010, 2014). Comparable results were also shown by Samson et al. (1999) who carried out a similar experiment using STF and MTF. Dark-light transition at $30 \mu \mathrm{mol}$ photons $\mathrm{m}^{-2} \mathrm{~s}^{-1}$ 
was clearly separated based on the transient shape and the derived $F_{\mathrm{r} 1}{ }^{\prime} / F_{\mathrm{q}}{ }^{\prime}$ and $F_{\mathrm{r} 2}{ }^{\prime} / F_{\mathrm{q}}{ }^{\prime}$ values (Fig. 8). The strong initial response upon illumination appears to represent transition from the dark-adapted state of inactive electron transport to a light-stimulated state of engaged electron transport, e.g., activation of RUBISCO in the first few minutes of light acclimation (Kono and Terashima 2014). In conclusion, $F_{\mathrm{q}}{ }^{\prime} / F_{\mathrm{m}}{ }^{\prime}$ derived by $\mathrm{FRRF}_{0.75 \mathrm{~ms}}$ approximate $F_{\mathrm{q}}{ }^{\prime} / F_{\mathrm{m}}{ }^{\prime}$ values derived by STF or MTF.

The $F_{\mathrm{m}-\mathrm{ST}}$ and $F_{\mathrm{m}-\mathrm{MT}}$ signal, along with $F_{\mathrm{v}} / F_{\mathrm{m}}$ and NPQ, are the most common photosynthetic parameters used in ChlF-assisted plant phenomics (Furbank and Tester 2011). These properties are relatively easy to measure by using existing ChlF techniques, and they are extremely sensitive to a range of photo-physiological properties of plants. At the same time, the $F_{\mathrm{m}}$ responses are rather non-specific, requiring additional information to identify the affected photosynthetic mechanisms (Kalaji et al. 2014). In addition, their direct responses to irradiance levels require that these parameters are measured under well-defined light conditions (generally in the dark, with pre-defined periods of dark adaptation), limiting their applications as reporters of physiological conditions under highly variable, natural light conditions. However, the properties of the photosynthetic electron transport from $\mathrm{Q}_{\mathrm{A}}$ towards PSI (expressed as $F_{\mathrm{r} 2}{ }^{\prime} / F_{\mathrm{q}}{ }^{\prime}$ ) remain well-constrained under different ambient light intensities (Fig. 8c). The possibility for automation and measurements in the light using the LIFT method will make it possible to monitor the dynamics of photosynthetic traits under natural conditions.

\section{Conclusion}

Simultaneous measurements of $F_{\mathrm{v}} / F_{\mathrm{m}}$ (respective $F_{\mathrm{q}}{ }^{\prime} / F_{\mathrm{m}}{ }^{\prime}$ ) and the kinetics of electron transport between PSII towards PSI expressed as $F_{\mathrm{r} 1,2} / F_{\mathrm{v}}$ (respective $F_{\mathrm{r} 1,2}{ }^{\prime} / F_{\mathrm{q}}{ }^{\prime}$ ) parameter provided more detailed information about the photosynthetic apparatus detecting differences in a wide range of physiological conditions. Performing these measurements noninvasively with high time resolution under natural environmental conditions has the potential to improve the efficacy of the photosynthetic phenotyping, while contributing to the advancement of knowledge about photosynthesis and its regulation.

Acknowledgements We would like to thank Angelina Steier for LIFT instrument maintenance. Beate Uhlig, Katharina Wolter-Heinen and Christian Jungmann are acknowledged for greenhouse management and for ensuring optimal plant growth conditions.

Funding This study was performed within the German Plant Phenotyping Network (DPPN) which is founded by the German Federal Ministry for Education and Research (BMBF). Project Identification
Number is BMBF 031A053. The work was partly supported (I.V. and A.u.R.) by the Hungarian Ministry for National Economy (Grant No. GINOP-2.3.2-15-2016-00037).

\section{Compliance with ethical standards}

Conflict of interest The authors declare that they have no conflict of interest.

Open Access This article is distributed under the terms of the Creative Commons Attribution 4.0 International License (http://creativeco mmons.org/licenses/by/4.0/), which permits unrestricted use, distribution, and reproduction in any medium, provided you give appropriate credit to the original author(s) and the source, provide a link to the Creative Commons license, and indicate if changes were made.

\section{References}

Ananyev G, Dismukes GC (2005b) How fast can Photosystem II split water? Kinetic performance at high and low frequencies. Photosynth Res 84:355-365. https://doi.org/10.1007/s1112 0-004-7081-1

Ananyev G, Kolber ZS, Klimov D et al (2005a) Remote sensing of heterogeneity in photosynthetic efficiency, electron transport and dissipation of excess light in Populus deltoides stands under ambient and elevated $\mathrm{CO}_{2}$ concentrations, and in a tropical forest canopy, using a new laser-induced fluorescence transient device. Glob Change Biol 11:1195-1206. https://doi.org/10.111 1/j.1365-2486.2005.00988.x

Baker NR (2008) Chlorophyll fluorescence: a probe of photosynthesis in vivo. Annu Rev Plant Biol 59:89-113. https://doi.org/10.1146/ annurev.arplant.59.032607.092759

Belyaeva NE, Schmitt FJ, Paschenko VZ et al (2014) Model based analysis of transient fluorescence yield induced by actinic laser flashes in spinach leaves and cells of green alga Chlorella pyrenoidosa Chick. Plant Physiol Biochem 77:49-59. https://doi. org/10.1016/j.plaphy.2014.01.017

Berthold DA, Babcock GT, Yocum CF (1981) A highly resolved, oxygen-evolving photosystem II preparation from spinach thylakoid membranes: EPR and electron-transport properties. FEBS Lett 134:231-234. https://doi.org/10.1016/0014-5793(81)80608-4

Bohme H, Reimer S, Trebst A (1971) The effect of dibromothymoquinone, an antagonist of plastoquinone, on non cyclic and cyclic electron flow systems in isolated chloroplasts. Z Naturforschung Part B-Chem Biochem Biophys Biol Verwandten Geb B 26:341-341+

Bowes JM, Crofts AR (1980) Binary oscillations in the rate of reoxidation of the primary acceptor of photosystem II. Biochim Biophys Acta BBA-Bioenerg 590:373-384. https://doi.org/10.1016/00052728(80)90208-X

Braslavsky SE, Holzwarth AR (2012) Role of carotenoids in photosystem II (PSII) reaction centers. Int J Thermophys 33:2021-2025. https://doi.org/10.1007/s10765-012-1274-1

Butler WL (1978) Energy distribution in the photochemical apparatus of photosynthesis. Annu Rev Plant Physiol 29:345-378

Cournac L, Redding K, Ravenel J et al (2000) Electron flow between photosystem II and oxygen in chloroplasts of photosystem. J Biol Chem 275:17256-17262. https://doi.org/10.1074/jbc.M9087 32199

de Wijn R, van Gorkom HJ (2001) Kinetics of electron transfer from QA to QB in photosystem II. Biochemistry 40:11912-11922. https ://doi.org/10.1021/bi010852r 
Deák Z, Sass L, Kiss É, Vass I (2014) Characterization of wave phenomena in the relaxation of flash-induced chlorophyll fluorescence yield in cyanobacteria. Biochim Biophys Acta BBA-Bioenerg 1837:1522-1532. https://doi.org/10.1016/j.bbabio.2014.01.003

Delosme R (1967) Étude de l'induction de fluorescence des algues vertes et des chloroplastes au début d'une illumination intense. Biochim Biophys Acta BBA-Bioenerg 143:108-128. https://doi. org/10.1016/0005-2728(67)90115-6

Delosme R, Joliot P (2002) Period four oscillations in chlorophyll a fluorescence. Photosynth Res 73:165-168. https://doi. org/10.1023/A:1020430610627

Diner BA (1977) Dependence of the deactivation reactions of Photosystem II on the redox state of plastoquinone pool a varied under anaerobic conditions. Equilibria on the acceptor side of Photosystem II. Biochim Biophys Acta BBA-Bioenerg 460:247-258. https://doi.org/10.1016/0005-2728(77)90211-0

Eshaghi S, Turcsányi E, Vass I et al (2000) Functional characterization of the PS II-LHC II supercomplex isolated by a direct method from spinach thylakoid membranes. Photosynth Res 64:179-187. https://doi.org/10.1023/A:1006404302573

Falkowski PG, Koblfzek M, Gorbunov M, Kolber Z (2004) Development and application of variable chlorophyll fluorescence techniques in marine ecosystems. In: Papageorgiou GC, Govindjee (eds) Chlorophyll a fluorescence: a signature of photosynthesis. Springer Netherlands, Dordrecht, pp 757-778

Feilke K, Yu Q, Beyer P et al (2014) In vitro analysis of the plastid terminal oxidase in photosynthetic electron transport. Biochim Biophys Acta BBA-Bioenerg 1837:1684-1690. https://doi. org/10.1016/j.bbabio.2014.07.016

Fiorani F, Schurr U (2013) Future scenarios for plant phenotyping. Annu Rev Plant Biol 64:267-291. https://doi.org/10.1146/annur ev-arplant-050312-120137

Furbank RT, Tester M (2011) Phenomics-technologies to relieve the phenotyping bottleneck. Trends Plant Sci 16:635-644. https://doi. org/10.1016/j.tplants.2011.09.005

Haldimann P, Tsimilli-Michael M (2005) Non-photochemical quenching of chlorophyll a fluorescence by oxidised plastoquinone: new evidences based on modulation of the redox state of the endogenous plastoquinone pool in broken spinach chloroplasts. Biochim Biophys Acta BBA-Bioenerg 1706:239-249. https://doi. org/10.1016/j.bbabio.2004.11.005

Hohmann-Marriott MF, Takizawa K, Eaton-Rye JJ et al (2010) The redox state of the plastoquinone pool directly modulates minimum chlorophyll fluorescence yield in Chlamydomonas reinhardtii. FEBS Lett 584:1021-1026. https://doi.org/10.1016/j. febslet.2010.01.052

Kalaji H, Schansker G, Ladle R et al (2014) Frequently asked questions about in vivo chlorophyll fluorescence: practical issues. Photosynth Res 122:121-158. https://doi.org/10.1007/s1112 0-014-0024-6

Kalaji HM, Schansker G, Brestic M et al (2017) Frequently asked questions about chlorophyll fluorescence, the sequel. Photosynth Res 132:13-66. https://doi.org/10.1007/s11120-016-0318-y

Kautsky H, Hirsch A (1931) Neue Versuche zur Kohlensäureassimilation. Naturwissenschaften 19:964-964. https://doi.org/10.1007/ BF01516164

Kolber ZS, Prasil O, Falkowski PG (1998) Measurements of variable chlorophyll fluorescence using fast repetition rate techniques: defining methodology and experimental protocols. Biochim Biophys Acta BBA-Bioenerg 1367:88-106. https://doi.org/10.1016/ s0005-2728(98)00135-2

Kono M, Terashima I (2014) Long-term and short-term responses of the photosynthetic electron transport to fluctuating light. J Photochem Photobiol B 137:89-99. https://doi.org/10.1016/j.jphot obiol.2014.02.016
Kurisu G, Zhang HM, Smith JL, Cramer WA (2003) Structure of the cytochrome $\mathrm{b}(6) \mathrm{f}$ complex of oxygenic photosynthesis: tuning the cavity. Science 302:1009-1014. https://doi.org/10.1126/scien ce. 1090165

Lazár D (2006) The polyphasic chlorophyll a fluorescence rise measured under high intensity of exciting light. Funct Plant Biol 33:930. https://doi.org/10.1071/FP05095

Lazár D (2013) Simulations show that a small part of variable chlorophyll a fluorescence originates in photosystem I and contributes to overall fluorescence rise. J Theor Biol 335:249-264. https://doi.org/10.1016/j.jtbi.2013.06.028

Lazár D, Tomek P, Ilik P, Naus J (2001) Determination of the antenna heterogeneity of photosystem II by direct simultaneous fitting of several fluorescence rise curves measured with DCMU at different light intensities. Photosynth Res 68:247-257. https ://doi.org/10.1023/A:1012973402023

Loriaux SD, Avenson TJ, Welles JM et al (2013) Closing in on maximum yield of chlorophyll fluorescence using a single multiphase flash of sub-saturating intensity. Plant Cell Environ 36:17551770. https://doi.org/10.1111/pce.12115

Magyar M, Sipka G, Kovács L et al (2018) Rate-limiting steps in the dark-to-light transition of photosystem II-revealed by chlorophyll-a fluorescence induction. Sci Rep 8:2755. https:// doi.org/10.1038/s41598-018-21195-2

Malkin S, Kok B (1966) Fluorescence induction studies in isolated chloroplasts I. Number of components involved in the reaction and quantum yields. Biochim Biophys Acta BBA-Biophys Photosynth 126:413-432. https://doi.org/10.1016/09266585(66)90001-X

Müh F, Glöckner C, Hellmich J, Zouni A (2012) Light-induced quinone reduction in photosystem II. Photosyst II 1817:44-65. https://doi.org/10.1016/j.bbabio.2011.05.021

Nedbal L, Trtílek M, Kaftan D (1999) Flash fluorescence induction: a novel method to study regulation of photosystem II. J Photochem Photobiol B 48:154-157. https://doi.org/10.1016/S1011 -1344(99)00032-9

Ögren E, Baker NR (1985) Evaluation of a technique for the measurement of chlorophyll fluorescence from leaves exposed to continuous white light. Plant Cell Environ 8:539-547. https:// doi.org/10.1111/j.1365-3040.1985.tb01691.x

Osmond B, Chow WS, Wyber R et al (2017) Relative functional and optical absorption cross sections of PSII and other photosynthetic parameters monitored in situ, at a distance with a time resolution of a few seconds, using a prototype light induced fluorescence transient (LIFT) device. Funct Plant Biol. https:// doi.org/10.1071/FP17024

Oxborough K, Moore CM, Suggett DJ et al (2012) Direct estimation of functional PSII reaction center concentration and PSII electron flux on a volume basis: a new approach to the analysis of fast repetition rate fluorometry (FRRf) data. Limnol OceanogrMethods 10:142-154. https://doi.org/10.4319/lom.2012.10.142

Pérez-Navarro M, Neese F, Lubitz W et al (2016) Recent developments in biological water oxidation. Biocatal Biotransform Bioinorg Chem 31:113-119. https://doi.org/10.1016/j. cbpa.2016.02.007

Petrouleas V, Crofts A (2005) The iron-quinone acceptor complex. In: Wydrzynski T, Satoh K, Freeman J (eds) Photosystem II. Springer, Dordrecht, pp 177-206

Pieruschka R, Klimov D, Kolber ZS, Berry JA (2010) Monitoring of cold and light stress impact on photosynthesis by using the laser induced fluorescence transient (LIFT) approach. Funct Plant Biol 37:395-402. https://doi.org/10.1071/fp09266

Pieruschka R, Albrecht H, Muller O et al (2014) Daily and seasonal dynamics of remotely sensed photosynthetic efficiency in tree canopies. Tree Physiol 34:674-685. https://doi.org/10.1093/treep hys/tpu035 
Prášil O, Kolber ZS, Falkowski PG (2018) Control of the maximal chlorophyll fluorescence yield by the QB binding site. Photosynthetica. https://doi.org/10.1007/s11099-018-0768-X

Raesch A, Muller O, Pieruschka R, Rascher U (2014) Field Observations with laser-induced fluorescence transient (LIFT) method in barley and sugar beet. Agriculture 4:159-169

Rascher U, Nedbal L (2006) Dynamics of photosynthesis in fluctuating light-commentary. Curr Opin Plant Biol 9:671-678. https://doi. org/10.1016/j.pbi.2006.09.012

Robinson HH, Crofts AR (1983) Kinetics of the oxidation-reduction reactions of the photosystem II quinone acceptor complex, and the pathway for deactivation. FEBS Lett 153:221-226. https:// doi.org/10.1016/0014-5793(83)80152-5

Robinson C, Suggett DJ, Cherukuru N et al (2014) Performance of fast repetition rate fluorometry based estimates of primary productivity in coastal waters. J Mar Syst 139:299-310. https://doi. org/10.1016/j.jmarsys.2014.07.016

Samson G, Bruce D (1996) Origins of the low yield of chlorophyll a fluorescence induced by single turnover flash in spinach thylakoids. Biochim Biophys Acta BBA-Bioenerg 1276:147-153. https://doi.org/10.1016/0005-2728(96)00072-2

Samson G, Prášil O, Yaakoubd B (1999) Photochemical and thermal phases of chlorophyll a fluorescence. Photosynthetica 37:163182. https://doi.org/10.1023/A:1007095619317

Schansker G, Tóth SZ, Strasser RJ (2005) Methylviologen and dibromothymoquinone treatments of pea leaves reveal the role of photosystem I in the Chl a fluorescence rise OJIP. Biochim Biophys Acta BBA-Bioenerg 1706:250-261. https://doi.org/10.1016/j. bbabio.2004.11.006

Schansker G, Tóth SZ, Kovács L et al (2011) Evidence for a fluorescence yield change driven by a light-induced conformational change within photosystem II during the fast chlorophyll a fluorescence rise. Biochim Biophys Acta BBA-Bioenerg 1807:10321043. https://doi.org/10.1016/j.bbabio.2011.05.022

Schansker G, Tóth S, Holzwarth A, Garab G (2014) Chlorophyll a fluorescence: beyond the limits of the QA model. Photosynth Res 120:43-58. https://doi.org/10.1007/s11120-013-9806-5

Schödel R, Irrgang K-D, Voigt J, Renger G (1999) Quenching of chlorophyll fluorescence by triplets in solubilized light-harvesting complex II (LHCII). Biophys J 76:2238-2248. https://doi. org/10.1016/S0006-3495(99)77380-7

Schreiber U (1986a) Detection of rapid induction kinetics with a new type of high-frequency modulated chlorophyll fluorometer. Photosynth Res 9:261-272. https://doi.org/10.1007/BF00029749

Schreiber U (2004) Pulse-amplitude-modulation (pam) fluorometry and saturation pulse method: an overview. In: Papageorgiou GC, Govindjee (eds) Chlorophyll a fluorescence: a signature of photosynthesis. Springer, Dordrecht, pp 279-319

Schreiber U, Schliwa U, Bilger W (1986b) Continuous recording of photochemical and non-photochemical chlorophyll fluorescence quenching with a new type of modulation fluorometer. Photosynth Res 10:51-62. https://doi.org/10.1007/bf00024185
Shinkarev V (2004) Photosystem II: oxygen evolution and chlorophyll a fluorescence induced by multiple flashes. In: Papageorgiou G, Govindjee (eds) Chlorophyll a fluorescence. Springer, Dordrecht, pp 197-229

Steffen R, Christen G, Renger G (2001) Time-resolved monitoring of flash-induced changes of fluorescence quantum yield and decay of delayed light emission in oxygen-evolving photosynthetic organisms. Biochemistry 40:173-180

Strasser BJ (1997) Donor side capacity of Photosystem II probed by chlorophyll a fluorescence transients. Photosynth Res 52:147-155. https://doi.org/10.1023/A:1005896029778

Strasser RJ, Srivastava A, Govindjee (1995) Polyphasic chlorophyll a fluorescence transient in plants and cyanobacteria. Photochem Photobiol 61:32-42. https://doi.org/10.1111/j.1751-1097.1995. tb09240.x

Suggett D, Kraay G, Holligan P et al (2001) Assessment of photosynthesis in a spring cyanobacterial bloom by use of a fast repetition rate fluorometer. Limnol Oceanogr 46:802-810

Taoka S, Crofts AR (1990) Two-electron gate in triazine resistant and susceptible Amaranthus hybridus. In: Baltscheffsky M (ed) Current research in photosynthesis: Proceedings of the VIIIth international conference on photosynthesis Stockholm, Sweden, August 6-11, 1989. Springer, Dordrecht, pp 547-550

Tomek P, Lazár D, Ilík P, Naus J (2001) Research note: On the intermediate steps between the $\mathrm{O}$ and $\mathrm{P}$ steps in chlorophyll a fluorescence rise measured at different intensities of exciting light. Funct Plant Biol 28:1151-1160

Tóth SZ, Schansker G, Strasser RJ (2005) In intact leaves, the maximum fluorescence level (FM) is independent of the redox state of the plastoquinone pool: a DCMU-inhibition study. Biochim Biophys Acta BBA-Bioenerg 1708:275-282. https://doi. org/10.1016/j.bbabio.2005.03.012

Tóth SZ, Schansker G, Garab G, Strasser RJ (2007a) Photosynthetic electron transport activity in heat-treated barley leaves: the role of internal alternative electron donors to photosystem II. Biochim Biophys Acta BBA-Bioenerg 1767:295-305. https://doi. org/10.1016/j.bbabio.2007.02.019

Tóth SZ, Schansker G, Strasser RJ (2007b) A non-invasive assay of the plastoquinone pool redox state based on the OJIP-transient. Photosynth Res 93:193. https://doi.org/10.1007/s11120-007-9179-8

Trtilek M, Kramer DM, Koblizek M, Nedbal L (1997) Dual-modulation LED kinetic fluorometer. J Lumin 72-4:597-599. https://doi. org/10.1016/s0022-2313(97)00066-5

Vass I, Kirilovsky D, Etienne AL (1999) UV-B radiation-induced donor- and acceptor-side modifications of photosystem II in the cyanobacterium Synechocystis sp. PCC 6803. Biochemistry 38:12786-12794. https://doi.org/10.1021/bi991094w

Vernotte C, Etienne AL, Briantais JM (1979) Quenching of the system II chlorophyll fluorescence by the plastoquinone pool. Biochim Biophys Acta-Bioenerg 545:519-527. https://doi. org/10.1016/0005-2728(79)90160-9 